\title{
Article \\ Effect of the Parking Lane Configuration on Vehicle Speeds in Home Zones in Poland
}

\author{
Alicja Sołowczuk *(i) and Przemysław Gardas \\ Department of Road and Bridge Engineering, West Pomeranian University of Technology in Szczecin, Szczecin \\ 71-311, Poland; pgardas@zut.edu.pl \\ * Correspondence: alicja.solowczuk@zut.edu.pl or kdim.zut@gmail.com
}

Received: 5 December 2019; Accepted: 8 January 2020; Published: 13 January 2020

\begin{abstract}
Nowadays, traffic calming measures that are designed to influence the drivers' behaviour in the first place and thus make them slow down (and increase the safety of traffic as a result) are used increasingly often in traffic engineering. As a rule of thumb, carefully planned street geometry and street furniture should advise the drivers of the traffic calmed area ahead of them, which makes them reduce the vehicle speed by influencing their perception. One of the most common treatments are road narrowings and horizontal deflections of the route of travel. The reduction of the vehicle speed increases the driver's central visual area, which results in earlier and easier spotting of pedestrians that are about to cross the roadway. A reduction of noise and exhaust emissions is an additional benefit. However, the current sustainable design guidelines are not specific regarding how often the route should be deflected by alternate parking lanes and how frequently they should be placed in the home zones (woonerven in Dutch) in order to achieve the desired reduction of vehicle speed, noise, pollution, and exhaust emissions. This being so, the authors carried out a speed survey research on a chosen street that includes woonerf design features, as typically used in Poland, with carriageway narrowings being created by parking lanes differently sited along its length. Several speed measuring devices were deployed to automatically and simultaneously measure and record the vehicle speeds and volume of traffic at different test locations. The measurement data were subjected to statistical analyses, including conventional statistical tests. The alternative hypothesis, proposing that the vehicle speeds depend on the configuration of parking lanes and carriageway narrowings was confirmed in almost all cases. The results have confirmed that the siting of parking lanes is a relevant factor as far as speed reduction is concerned, with the degree of this reduction depending on the remaining travel lane width.
\end{abstract}

Keywords: home zone (woonerf), vehicle speed reduction; parking lane; carriageway narrowing

\section{Introduction}

In built-up areas calming of traffic in order to improve road safety is becoming an issue in an ever growing number of places. This problem became particularly acute in the $20^{\text {th }}$ century, when the social and recreational functions of urban streets were seriously disturbed by an increasing volume of vehicular traffic travelling at higher speeds and its increasing share in overall traffic volume, which affects the overall safety of traffic. The ever growing volumes of traffic in urban areas result in growing problems that are related to the road system capacity, the safety of road users and increased noise and atmospheric emissions. The following measures are implemented in response to this problem in places, including the outskirts of towns, residential developments, and districts: closing selected streets to vehicular traffic, one-waying [1-4], implementation of Tempo-30 [5,6], shared space [7], or living street [8] schemes. The last arrangement has different names depending on the country and language [8], and it is called "woonerf" (plural: "woonerven") in Dutch, "home zone", "living street", 
or "shared zone" in English, "Wohnstraße" in German, "quartier résidentiel" in French, and "Dutch Street" in some other countries. In the further part hereof, only the Dutch term woonerf will be used to avoid confusion [8].

The woonerf movement was initiated in the Netherlands in 1970s with the objective of reinstating the lost balanced coexistence between the local residents and vehicular traffic [9] and it led to the introduction of basic legal regulations and design guidelines in 1989 [10]. According to [10-18], the maximum allowed vehicle speed is comparable to the walking speed in woonerven. Similarly to the name of such arrangement, the exact value also differs between the countries, depending on the applicable highway code provisions. For example, according to [8], the speed limits in woonerf areas are: $30 \mathrm{~km} / \mathrm{h}$ in the UK, $15 \mathrm{~km} / \mathrm{h}$ in the Netherlands, Norway, and Switzerland, and $20 \mathrm{~km} / \mathrm{h}$ in most other countries.

The following guidelines applicable to woonerven are defined in [10-18]:

1. The drivers must be made to observe the speed limit given in the local highway code by installation of the different traffic calming measures, so that pedestrians and children playing in any place of the carriageway can feel secure. Generally, the relevant guidelines refer to the walking speed as applicable to the determination of the maximum allowed speed of vehicular traffic.

2. On some section of the street, horizontal design features should be implemented to communicate to the cyclists and drivers the priority of pedestrian traffic.

3. The point of entry to a woonerf from a regular street with a higher speed limit should be easily recognisable and specifically marked, for example using entrance gateways to communicate to the drivers the change in traffic priority and also warn them of the possible presence of pedestrians and children playing in any place of the carriageway. Only uncontrolled intersections should be designed within the woonerf limits. Subject to reduction of vehicle speed to the desired level, a $12 \mathrm{~m}$ stopping sight distance must be ensured, so that the drivers can sufficiently early spot the pedestrians and children playing in the street.

4. The previously recommended vertical shifts in the carriageway, such as speed humps [19], speed bumps ("sleeping policeman") [19], or "Eselsrücken" [15] are being phased out [8]. However, they are still recommended in the Polish design guidelines [9].

5. As a general rule, marked pedestrian crossings are not used, since the whole carriageway area is available to pedestrians who have priority throughout the woonerf area. That said, pedestrian crossings are acceptable where specifically needed to ensure the safety of pedestrians [14,15].

6. Typical street kerbs should not separate walkways. They are only acceptable if they existed there before conversion of the street to woonerf area and were not removed at that time.

7. There are no bike paths in woonerven since priority is given to pedestrian.

8. The travel lanes should only go straight on short sections. Planters are often placed along the streets, both upstream and downstream of the parking lanes or parking spaces, as a horizontal deflection of the carriageway. Some other traffic calming measures are mentioned below.

9. Parking only allowed in designated places. In Poland a parking fine is charged for illegal parking in woonerven [9].

The parking lanes or parking bays can be separated by (see Figure 1): bollards, various barriers, street furniture and hard landscaping, change of surfacing material, pavement markings, isolated trees, or strip planter beds. The primary function of designating the parking lanes or bays is to direct the traffic and emphasize the respective street furniture and structural landscaping items to control speed and also protect trees and green areas. Such items are placed at the beginning and at the end of parking lanes or places to signal the carriageway narrowing to the driver to make him/her slow down that also at times when there are no parked cars parked there. 


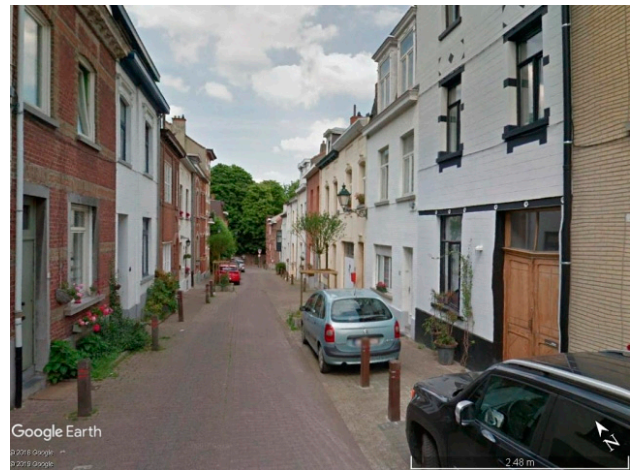

(a)

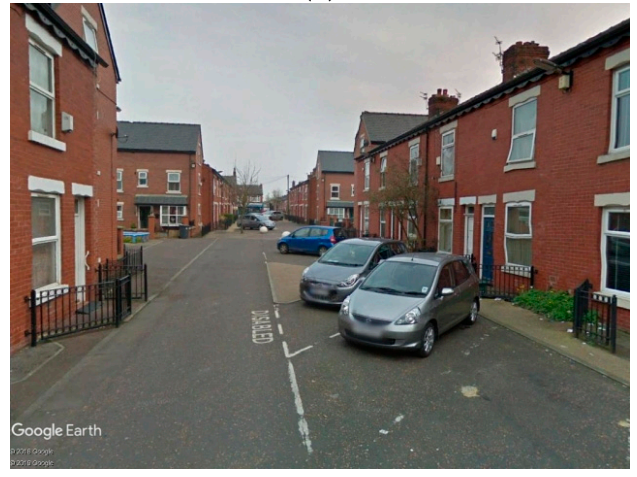

(c)

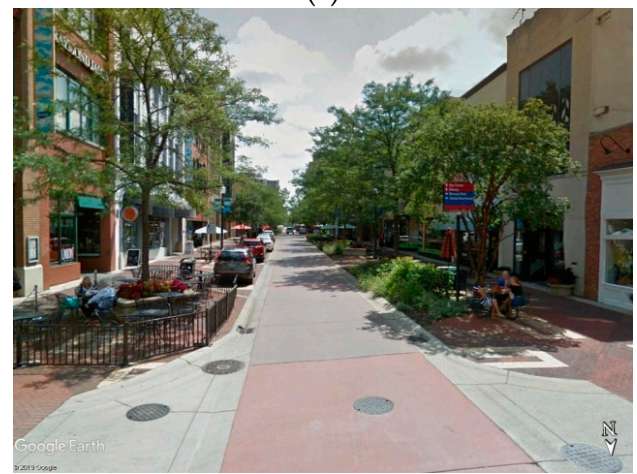

(e)

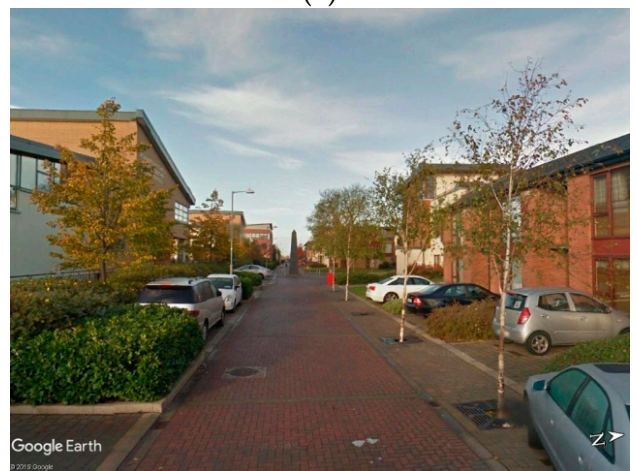

(g)

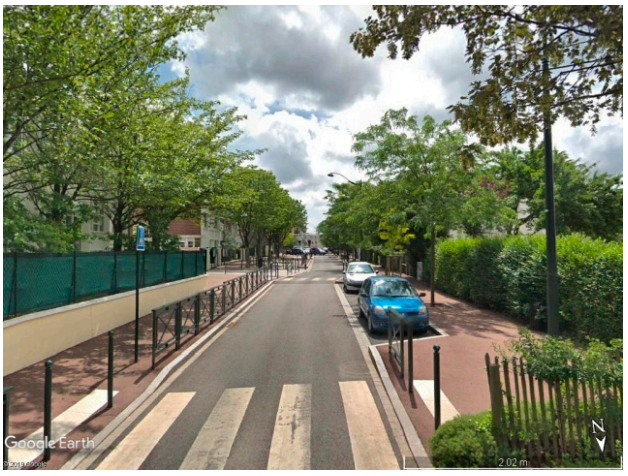

(b)

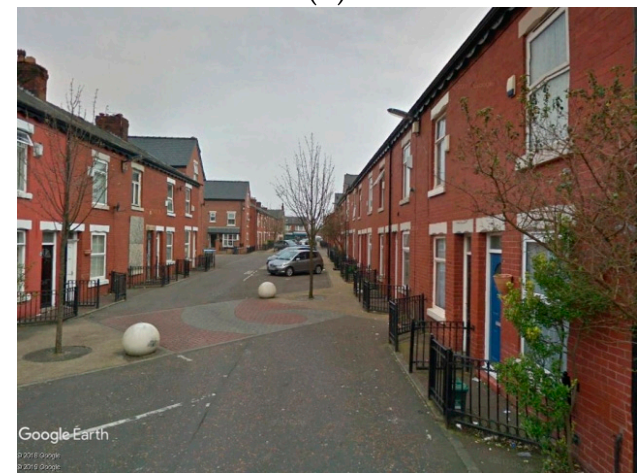

(d)

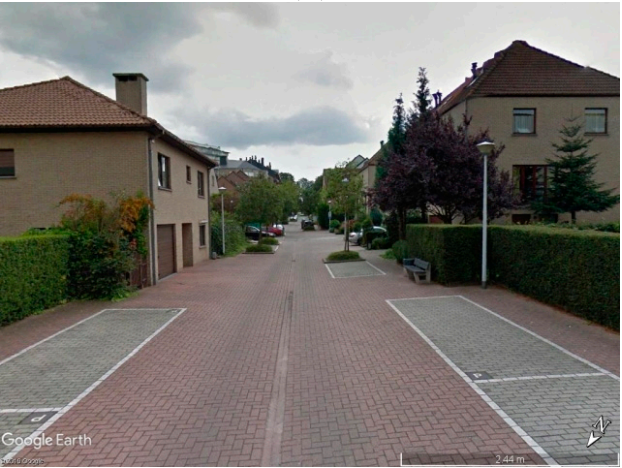

(f)

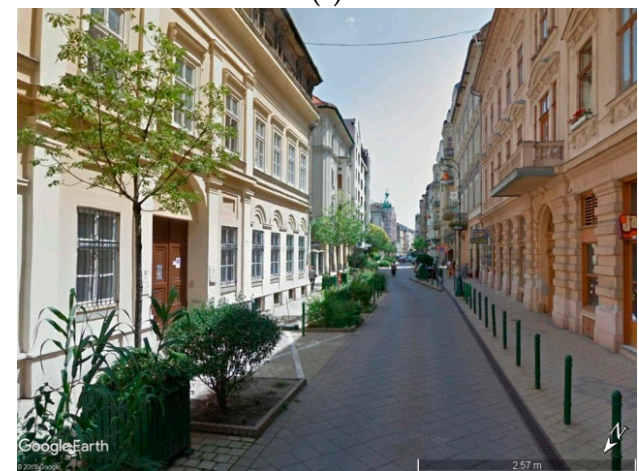

(h)

Figure 1. Methods of separating parking lanes/ places (photo courtesy Google Earth [20]): (a) Bollards; (b) Various barriers; (c) Street railings; (d) Offset ("twisted") chokers and parking bays alternating between the sides of the street; (e) Sets of street furniture and/or structural landscaping features (concrete balls and change of the surfacing material in this case); (f) Changes of the surfacing material and paving markings; (g) Single trees; and, (h) Various vegetation. 
Different national guidelines give slightly different principles of sustainable design of parking places in woonerven [10-15]. Most of them mention traffic volume as a factor that is highly relevant to woonerf design, which is most appropriately represented by the number of motor vehicle trips to and from each dwelling during the afternoon peak hour, a factor called the vehicular trip rate, maximum number of dwellings or single-family houses, translating to the required number of parking bays, and the expected parking duration.

In places where woonerf implementation [16] is planned, the UK guidelines [12] limit the roadway narrowing length to $400 \mathrm{~m}$ in general, $600 \mathrm{~m}$ being the maximum allowed length. It is recommended to make sure that fire engine and rubbish lorry access is ensured at all times. Drivers of larger vehicles, such as furniture lorries, are required to drive with particular caution. As regards the remaining dimensions, the guidelines used in other countries follow the provisions of the Dutch guidelines [10,11]. In addition, if the local residents are involved in the street space design process, then they should be consulted as to the siting of street furniture and outdoor play equipment. The following table presents some design guidelines, being prepared following a review of the above-mentioned national guidelines, as modified and amended from time to time, including conclusions drawn on the basis of a few years of experience with woonerven in these countries (Table 1).

Table 1. Selected woonerf design guidelines.

\begin{tabular}{|c|c|c|}
\hline Country: & $\begin{array}{c}\text { Main Geometric } \\
\text { Parameters }^{1}\end{array}$ & Comments \\
\hline UK [12] & $\begin{array}{c}B e \geq 3 \mathrm{~m} \\
B \geq 4.5 \mathrm{~m} \\
A e\end{array}$ & $\begin{array}{l}\text { The length of horizontal narrowing of the streets on both sides to the } \\
\text { width of Be } \geq 3 \mathrm{~m} \text { should not exceed the length of } 40 \mathrm{~m} \text {. Checking of } \\
\text { emergency corridors is recommended as an obligatory requirement. } \\
\text { The interval between the subsequent narrowings must not be longer } \\
\text { than } 30 \mathrm{~m} \text {. } \\
\text { The maximum traffic volume during peak hours must be less than } \\
100 \mathrm{v} / \mathrm{h} \text {. } \\
\text { The recommended treatments to delineate parking places include } \\
\text { bollards, railings or plantings. The parking spaces should be spaced } \\
\text { away from the building fronts by at least } 1.5 \mathrm{~m} \text {. }\end{array}$ \\
\hline $\begin{array}{c}\text { Netherlands } \\
\text { [11] }\end{array}$ & $\begin{array}{c}B e=3 \mathrm{~m} \\
B e=5 \mathrm{~m} \\
A e\end{array}$ & $\begin{array}{l}\text { On a one-way street. } \\
\text { On a two-way street. } \\
\text { The maximum interval between the subsequent carriageway } \\
\text { narrowings must not exceed } 50 \mathrm{~m} \text {. } \\
\text { Posting a } 15 \mathrm{~km} / \mathrm{h} \text { speed limit sign is recommended as an additional } \\
\text { measure. It is recommended to provide street furniture, planters } \\
\text { and outdoor play structures to communicate to drivers that this is a } \\
\text { place where residents and kids playing in the streets are the primary } \\
\text { users. Separated walkways are allowed. }\end{array}$ \\
\hline Belgium [13] & & $\begin{array}{l}\text { The maximum traffic volume during peak hours: less than } 500 \mathrm{v} / \mathrm{h} \text {. } \\
\text { Vertical treatments are required at the end of carriageway narrowing } \\
\text { or horizontal deflection to act on the drivers when there are no cars } \\
\text { parked there. Characteristic gateways should be placed to } \\
\text { communicate pedestrian priority to the drivers entering the zone. } \\
\text { These "gateways" can be made using trees, symbolic elements, etc. } \\
\text { Pedestrians can use the entire width of the carriageway and is not } \\
\text { needed to delineate the travel lanes or vary the elevations of } \\
\text { surfaces. Siting of children play areas and parking places should } \\
\text { follow the principles of sustainable design. }\end{array}$ \\
\hline Germany [21] & $\begin{array}{c}B e \\
L v=f(T v)\end{array}$ & $\begin{array}{l}\geq 3 \mathrm{~m} \\
\text { A graph showing relationship between } L v \text { and } T v \text { for different } \\
\text { values of } B \text { is given in the German guidelines. For soft landscaping } \\
\text { appropriate species should be chosen, taking account of the local } \\
\text { conditions. Young trees should be adequately protected. }\end{array}$ \\
\hline
\end{tabular}


Table 1. Cont.

\begin{tabular}{|c|c|c|}
\hline Country: & $\begin{array}{c}\text { Main Geometric } \\
\text { Parameters }{ }^{1}\end{array}$ & Comments \\
\hline $\begin{array}{c}\text { Switzerland } \\
\text { [15] }\end{array}$ & $\begin{array}{c}L v=f(T v) \\
A v \\
L e \\
A e \\
D e\end{array}$ & $\begin{array}{l}\text { The } L v=f(T v) \text { relationship from [22] is further developed and } \\
\text { supplemented with division into ranges of } T v<B \text { and } T v>B \text {. } \\
10 \mathrm{~m} \leq A v \leq 30 \mathrm{~m} \text {, depending on the local conditions. } \\
\text { The carriageway narrowings can be shorter, i.e., } 5-10 \mathrm{~m} \text { or longer, } \\
\text { i.e., } 10-50 \mathrm{~m} \text { long, this depending on the local conditions. } \\
\text { The carriageway narrowings should be spaced by between } 30 \mathrm{~m} \text { and } \\
50 \mathrm{~m} \text {, depending on the local conditions. } \\
\text { The minimum distance of the narrowing and the junction is } 15 \mathrm{~m} \text { for } \\
\text { speed limit of } v_{\max }=50 \mathrm{~km} / \mathrm{h} \text { or } 0 \mathrm{~m} \text { in the case of a woonerf street. }\end{array}$ \\
\hline
\end{tabular}

${ }^{1}$ The designations in Table 1 are the same as in Figure 2.

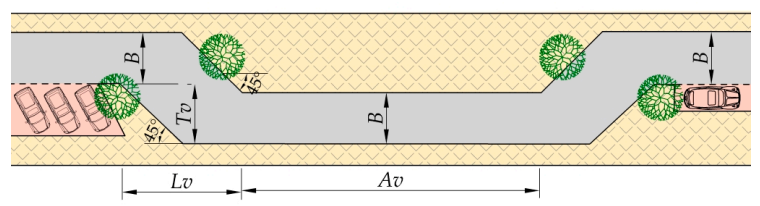

(a)

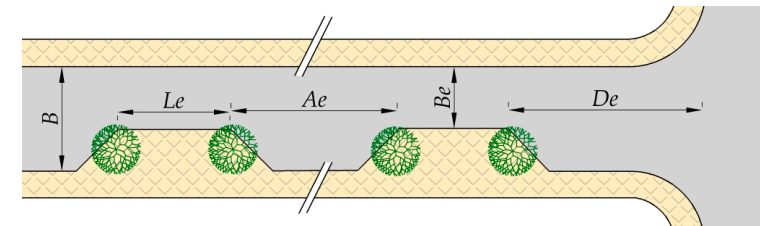

(b)

Figure 2. Image showing the meaning of designations concerning horizontal deflections and placement of carriageway narrowings in woonerven as per Table 1: (a) Horizontal deflection parameters; (b) Parameters defining the required intervals between subsequent carriageway narrowings.

The UK guidelines [12] mention that a speed reduction to $10 \mathrm{mph}$ (i.e., ca. $16 \mathrm{~km} / \mathrm{h}$ ) was obtained by implementing various parking arrangements in the Northmoor residential zone of Manchester, placed on one side or alternating between the sides of the streets, yet in all cases accompanied by horizontal deflection. The above-described arrangements used in Northmoor are often referred to in other national guidelines [10,11,13-17]. Two examples of parking arrangements in Northmoor, Manchester are presented in Figure 3, below.

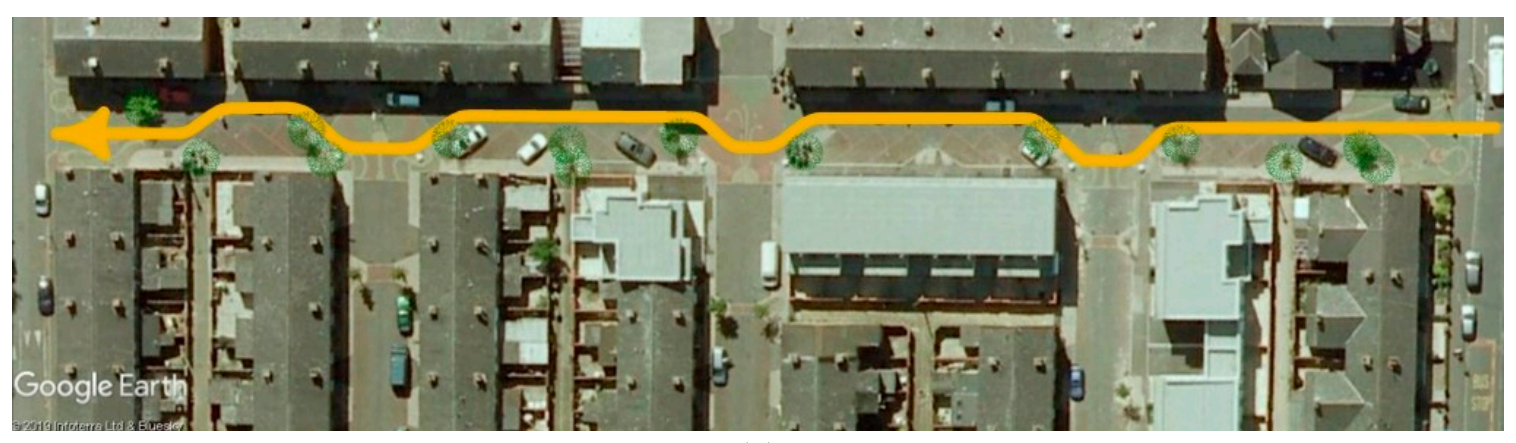

(a)

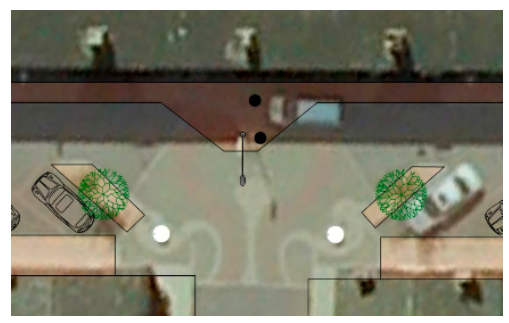

(b)

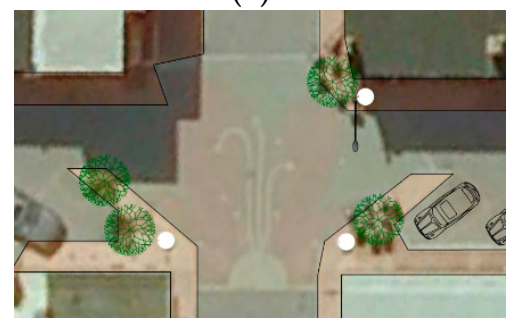

(c)

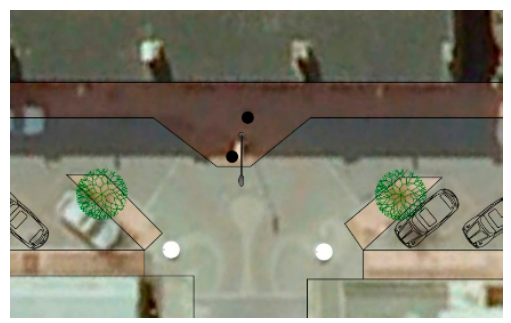

(d)

Figure 3. Cont. 


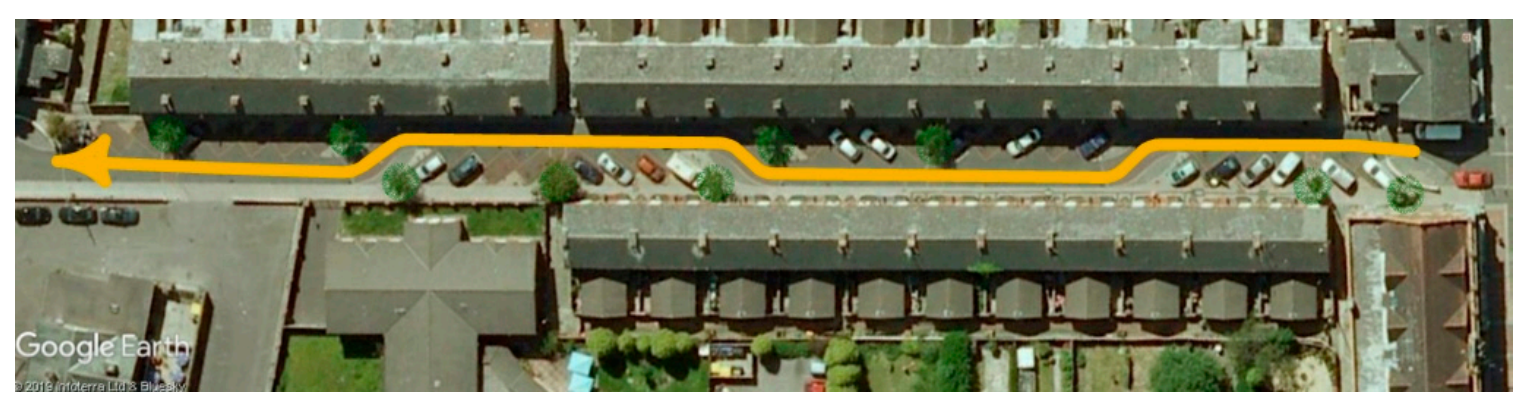

(e)

Figure 3. Various types of horizontal deflections in woonerf areas (drawn on the Google Earth map [20]): (a) Skew parking places (max 3xPP) and uncontrolled junctions with side streets; (b) Horizontal deflection details on the left-hand junction; (c) Horizontal deflection details on the central junction; (d) Horizontal deflection details on the right-hand junction; (e) Skew parking places on both sides of the street (max $4 \times P P)$.

On the other hand, Swiss guidelines [15], besides various guidelines concerning use of kerbing and drainage, provide detailed recommendations concerning parking design to obtain horizontal deflections. Similar principles concerning the design parameters of horizontal shifting of the carriageway and use of chicanes are given also in the UK [22] and Dutch [23] guidelines, yet they concern more the Tempo 30 zones, and relate to ensuring the passage and passing of large vehicles and busses. The Swiss guidelines [15], in turn, focus on woonerf design and ensuring the passage and passing of passenger cars. It is worth noting that all of the reviewed woonerf design guidelines require placing permanent structure before the parking places to make the drivers pay attention to the entire width of the public space, even without any cars being parked there. Moreover, horizontal shifts in the carriageway should take into account the buildings and the sighting limits defined by them and they should not act as foreign objects in the street space. According to the sustainable design principles, parking places should linked to soft landscaping, street furniture, and cycle parking to avoid dominating the street space.

The speed reducing effect of horizontal shifts in the carriageway primarily depends on their geometry. As a rule of thumb, the shorter and deeper are the horizontal shifts, the better assessment of the road situation that they offer to the driver and the greater speed reduction can be obtained as a result. While taking this into account, the Swiss guidelines [15] give different travel lane widths on the narrowed sections for one-way and two-way traffic configurations (between $3.0 \mathrm{~m}$ and $5.5 \mathrm{~m}$ ). The recommended lengths of carriageway narrowings by parking lanes are also given: from 10 to $30 \mathrm{~m}$ with the maximum distance between subsequent narrowings being in the range of $10-50 \mathrm{~m}$. Depending on the parking lane configuration-skewed or parallel to the carriageway axis, translating to the narrowing depth $T v$, the Swiss guidelines [15] give the horizontal shift length $L v$, which, in addition, depends on the carriageway width $B$ (see Figure 2). The Dutch guidelines limit the parking length to max. $50 \mathrm{~m} \mathrm{[11],} \mathrm{where} \mathrm{length,} \mathrm{in} \mathrm{the} \mathrm{UK} \mathrm{guidelines} \mathrm{[12],} \mathrm{are} \mathrm{defined} \mathrm{by} \mathrm{the} \mathrm{number} \mathrm{of}$ cars parked parallel to each other, namely 4-6 (this giving a length range of 25-36 m) to avoid an impression of a tunnel as compared to the requirements given in the Swiss guidelines. Moreover, the UK guidelines [12] relate the carriageway width over the length of the carriageway narrowing $\mathrm{Be}$ to the angle of skew parking places, namely $3 \mathrm{~m}$ for $30^{\circ}, 4 \mathrm{~m}$ for $45^{\circ}$, and $4.5 \mathrm{~m}$ for $60^{\circ}$.

However, the above sustainable design principles are not always followed when woonerven are actually designed. Cheaper arrangements are often chosen due to the budget constraints of the street operator. It happens that, besides the relevant road signs placed at the entry and exit, the woonerf elements are limited to the parking lanes, without the additional horizontal shift treatments, i.e., plantings, bollards, railings, etc., with this being in contrast to the situations that are presented in Figures 1 and 3. In Poland, for example, the cheapest options are chosen, comprising carriageway narrowing and horizontal shifts that are imposed by parking lanes, which are only marked by line markings, without any upstream and downstream islands or the above-mentioned vertical treatments 
placed thereon. Taking this into account, the authors chose for a case study one of woonerf streets in which the carriageway narrowing was solely obtained with delineated parking lanes with the purpose to determine whether this arrangement could effectively reduce the speeds to $20 \mathrm{~km} / \mathrm{h}$, i.e., the level required for woonerven.

The literature review, as presented above, and conclusions of the studies that are presented in this article enabled the authors to propose the sustainable design process for woonerven, as presented in Figure 4 below. In relation to the planned implementation of woonerf scheme the following factors, in the authors' opinion, should be analysed in the first place (Stage 1), in line with the sustainable design principles (Figure 4): vehicle-pedestrian accidents, traffic volume, including its daily variations, pedestrian traffic volumes, current travel speeds. Stage 2 analysis should follow, covering three environmental factors, namely: the presence of public buildings, public space development, and type of buildings to determine which woonerf components are needed. The conclusions of the above-mentioned environmental analysis should be considered in the formulation of the woonerf design guidelines (Stage 3), covering the road design, recommended engineering traffic calming measures, and landscaping. The road engineering principles should be applied, as appropriate, to verify the need for and determine the locations of pedestrian crossings, parking lanes/ spaces, and private and public drive entrances. The use of horizontal shifts and elements imposing them can be ranged among either road engineering or traffic calming aspects of the woonerf design. Fences, gates, and traffic bollards, in turn, are considered by the authors to be solely related to traffic calming. Vertical traffic calming measures can also be considered, yet this depends on the provisions of the relevant national guidelines. The reason that they have not been included in Figure 4 is their absence in most of these guidelines. In the landscaping design, the authors included the needs of residents, including: outdoor play areas, architectural arrangements, street furniture design, and soft landscaping. The outcome of the analysis and prioritisation of the above-mentioned factors should, in the authors' opinion, be used to support a choice of woonerf or Tempo-30 zone scheme as the appropriate option for a given street. In all cases, speed surveys should be carried out to check the efficiency of treatments that are designed for new or existing woonerven. Depending on the survey results, going back to Stage 2 , in order to implement, appropriate revisions should be considered.

In Section 1 of this article the authors carried out a study of the woonerf design guidelines applied in the different countries. Section 2 describes the research subject and the methods of these analyses. Section 3 includes statistical inference with each sub-section presenting the results of a given test. Section 4 provides a synthetic discussion of results and Section 5 gives a summary of the case study performed for a chosen woonerf street. Section 5 also indicates additional traffic calming measures to facilitate obtaining the expected speed reduction. 


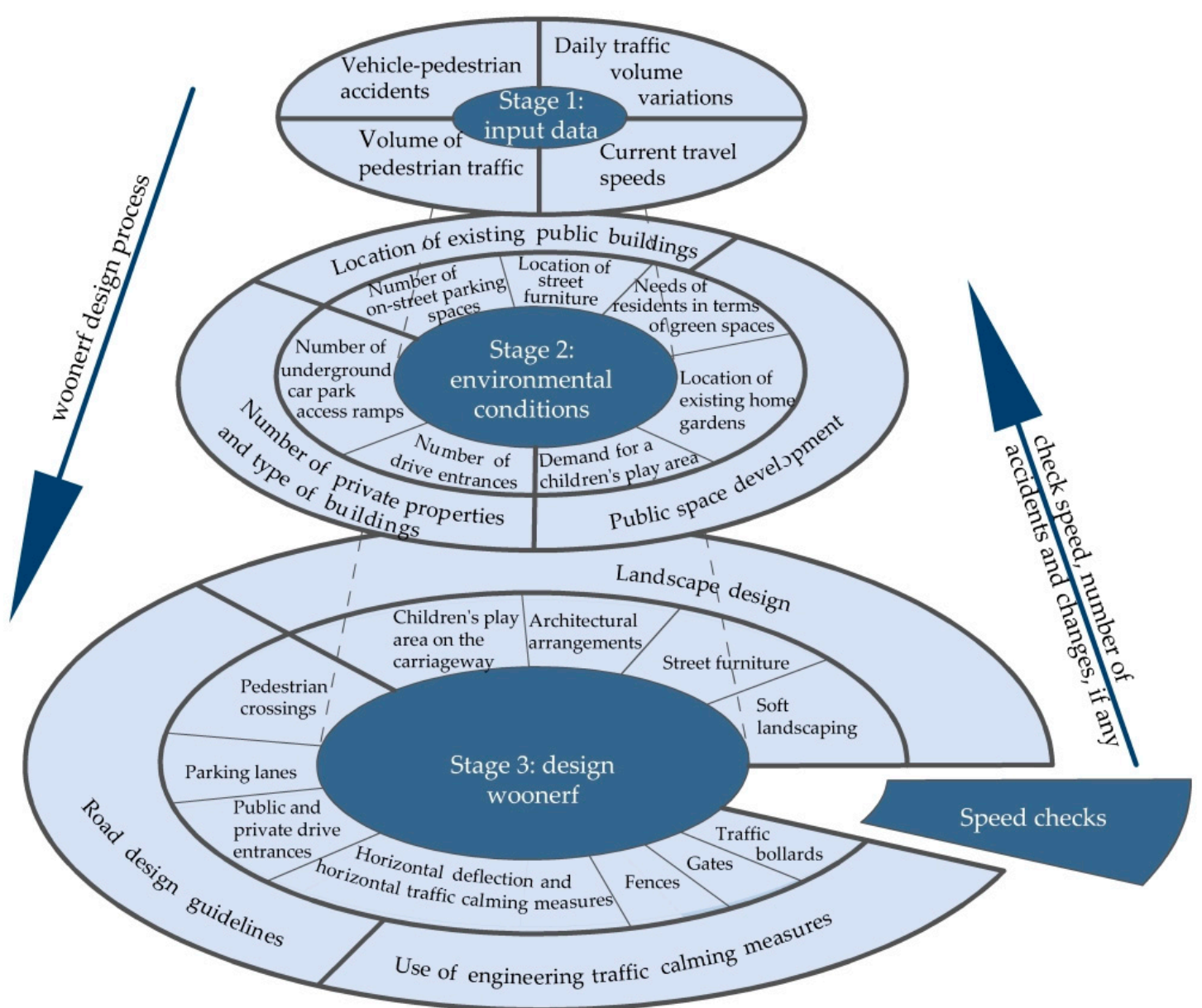

Figure 4. The proves of sustainable woonerf design proposed by the authors based on the output of analyses under this research.

\section{Materials and Methods}

The primary function of wonerven is to calm the traffic and change the traffic priority scheme. The reduction of speed to the desired level should be ensured by the implemented traffic calming measures. In Poland, however, woonerf schemes are implemented in the outskirts of towns and cities or in small residential estates just by placing the home zone sign and the streets are hardly ever adjusted to accommodate any outdoor play areas and take the residents' reactions into account. In a majority of cases, one will find there a street marked by start and end home zone signs, which is either completely devoid of any other woonerf design features or with features limited to just a few additional parking places, marked solely by pavement markings and the appropriate traffic signs placed in the adjacent walkway or beyond the carriageway limits. The latter situation applies to the street chosen for analysis. This is a bad engineering practice that is quite common in Poland, which has been observed by the authors (Figure 5). Therefore, the street under analysis is considered to be a good choice for analysing the effect of such parking lanes on the vehicle speeds. 


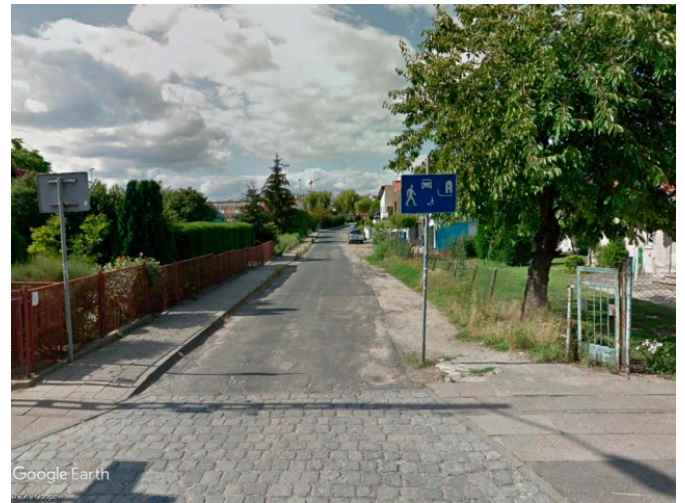

(a)

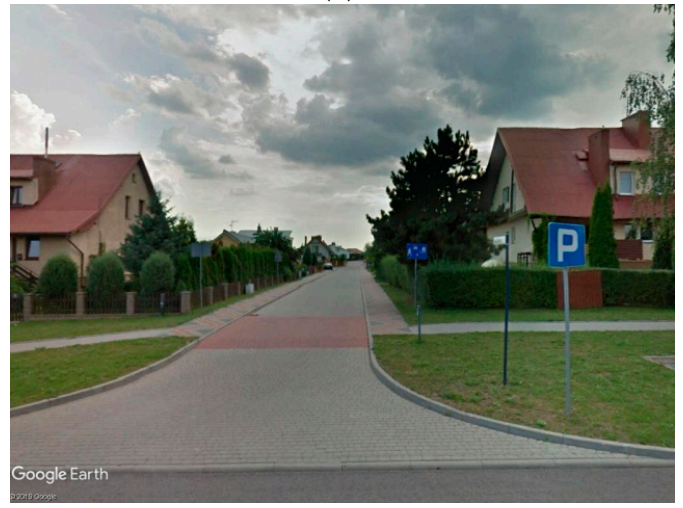

(c)

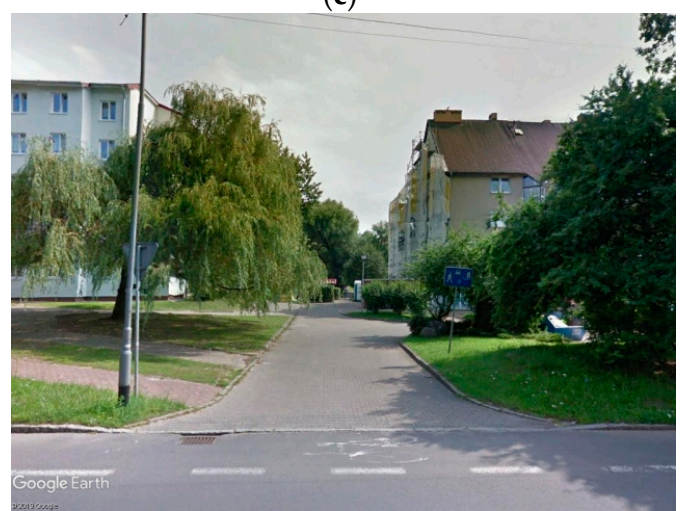

(e)

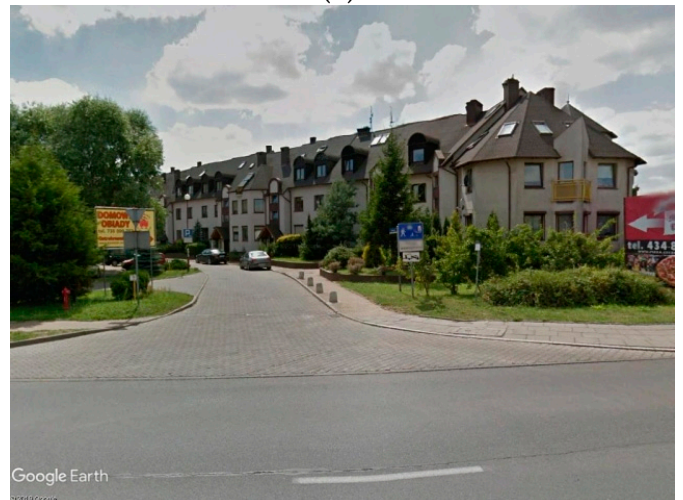

(g)

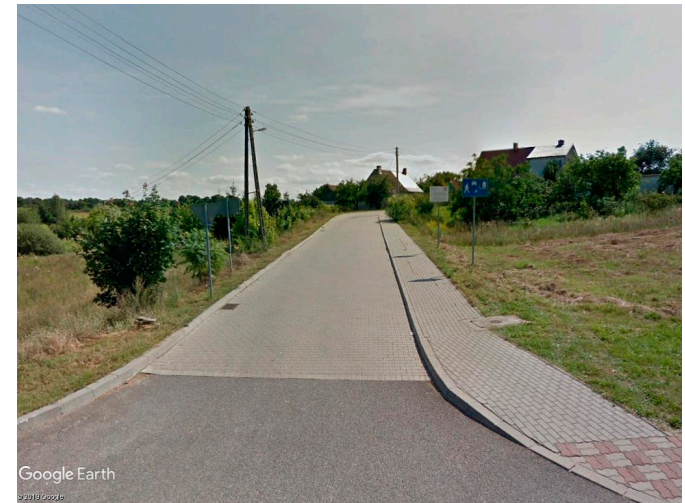

(b)

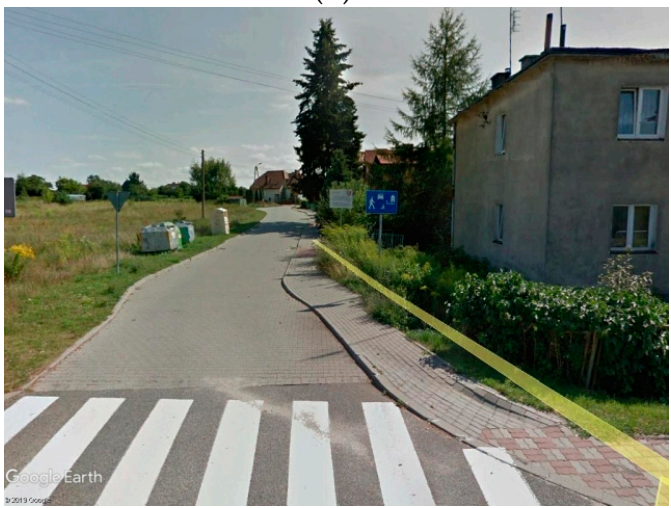

(d)

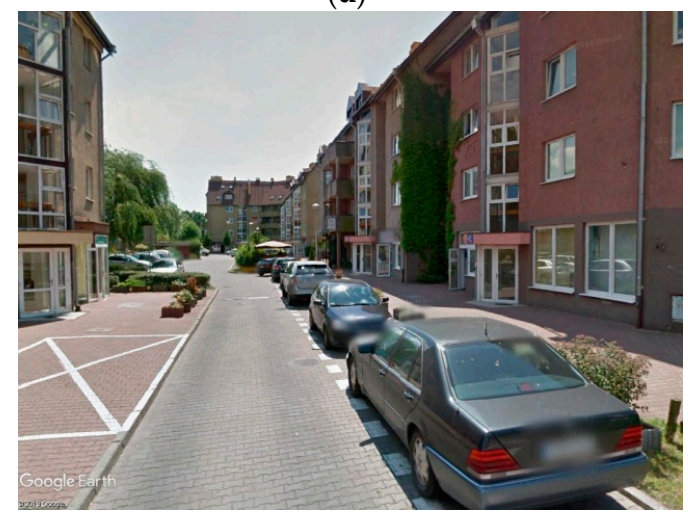

(f)

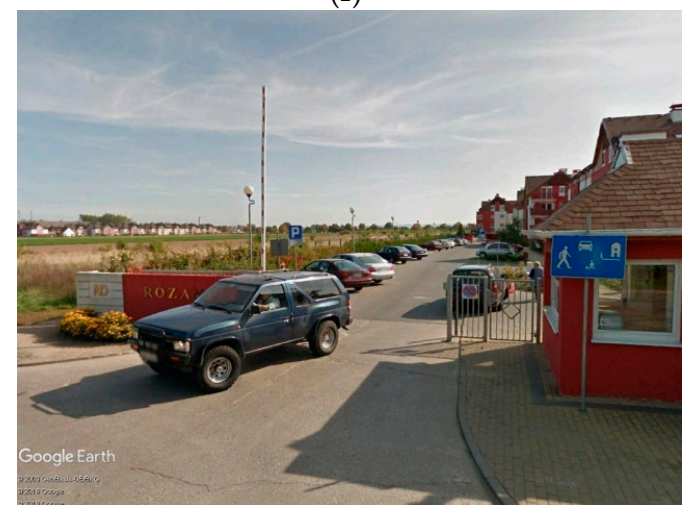

(h)

Figure 5. Examples of typical woonerf features used in Poland (photo courtesy Google Earth [20]): (a) Lubawska St., Gumieńce district of Szczecin; (b) Młyńska St., Chociwel (c) Tuwima St., Drawsko Pomorskie; (d) Robotnicza St., Chociwel (e) Łukasińskiego St., Szczecin; (f) Łukasińskiego St., Szczecin; (g); Ostrobramska St., Szczecin; and, (h) Różane housing estate. 
The authors carried out a round-the-clock speed survey at eight test stations on a chosen, representative Polish street in order to check whether the parking lanes PL and carriageway narrowing $B e$ without any further treatments except for line markings would bring about the desired speed reduction (Figure 6).

It is a local street of small importance in the local road network from the traffic volume point of view. Tempo-30 zones were implemented in the remaining streets of this residential community (Figure 6b). The only hospital driveway entry is from the through street running perpendicular to the woonerf street under analysis (Figure 6b). Ambulances, hospital personnel, and patients who have chosen to use metered parking lots located in the hospital premises also use this entry. Moreover, there are four normally closed emergency exits to the analysed street from the hospital expansion area.

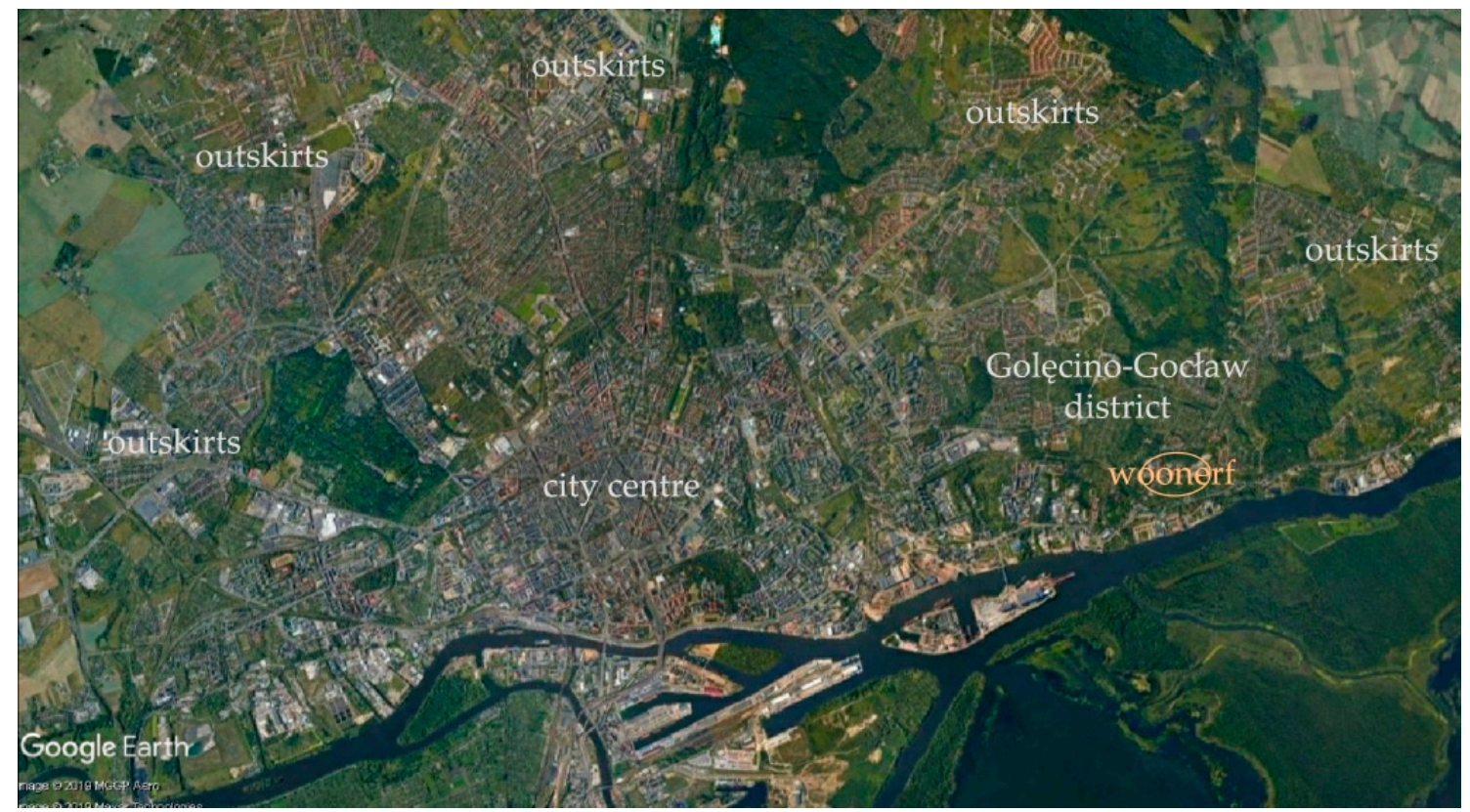

(a)

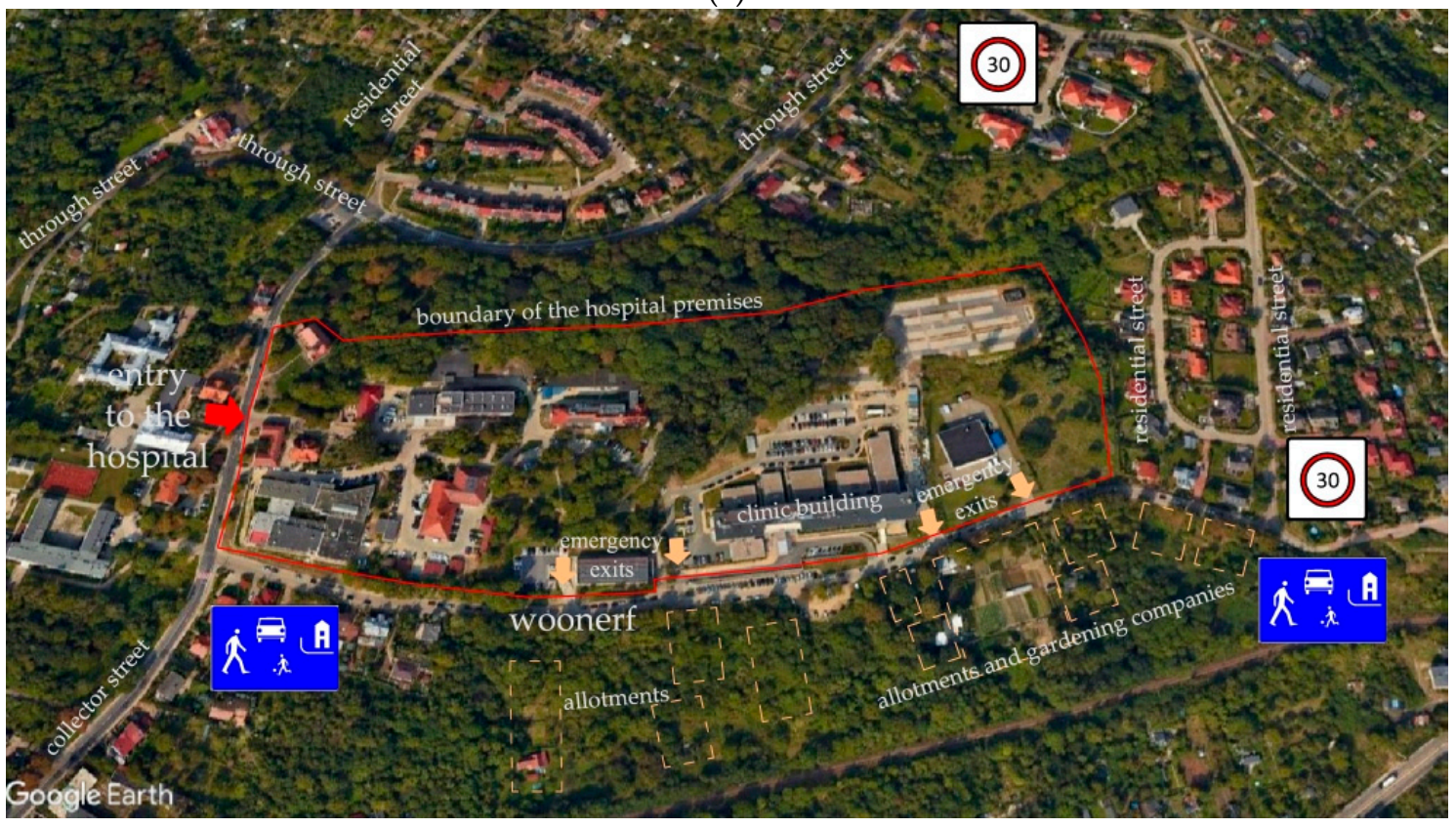

(b)

Figure 6. Cont. 


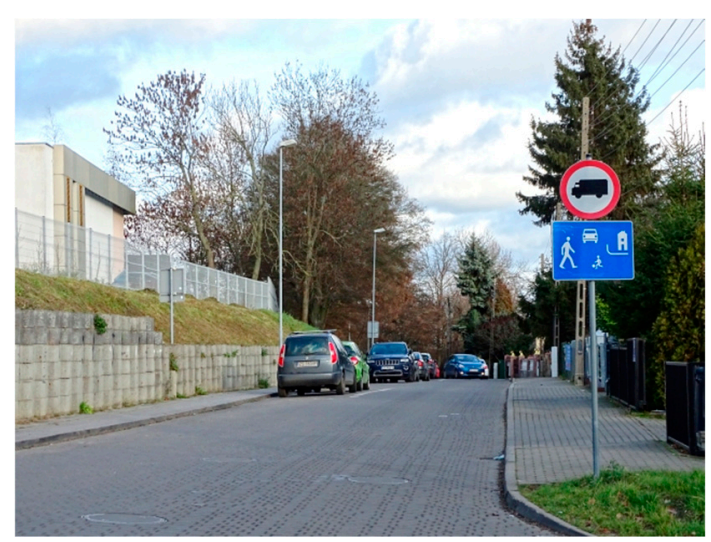

(c)

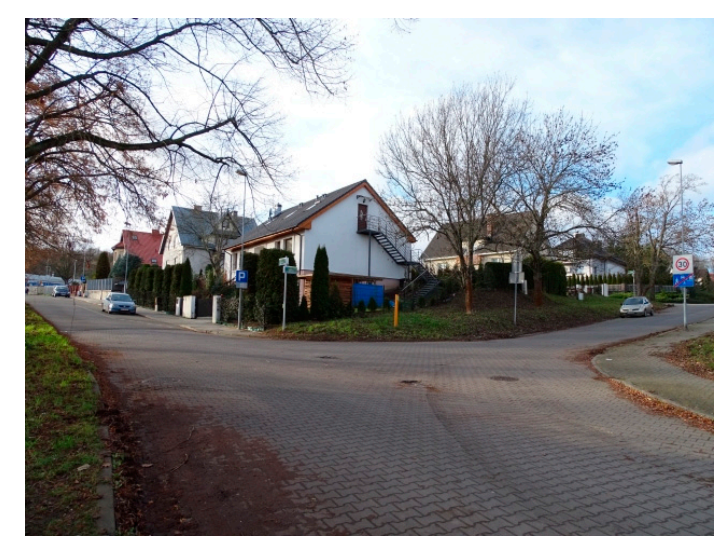

(d)

Figure 6. Outline description of the object of research (drawn on the Google Earth map [20]): (a) Location of the Goleccino-Gocław district with the woonerf street under analysis; (b) Surroundings and the road network around the analysed street with parking lanes; (c) Entry to the Home Zone area; and, (d) End of the Home Zone area.

In this street, the woonerf scheme was implemented a few years ago in relation to the expansion of the cancer hospital extending over almost the entire length of the street and to address the observed parking problems (Figure 7). With the new clinic building in place and after upgrading of the carriageway (in 2008-2011), whereby it was widened from $4 \mathrm{~m}$ to $6.1 \mathrm{~m}$ and obtained block paving in place of crushed stone surface, the driving conditions have improved, enabling travelling at 50-60 km/h. Although parking lots have been provided in the premises, most visitors would rather parking along the street to avoid cost of parking, especially when staying for a few hours. Quite a lot of outpatients, right after carriageway widening project used to park on lawns, thus creating a safety hazard and blocking access to allotments located on the opposite side of the street. With the purpose of improving the traffic conditions and avoiding the blocking of entries the city administration introduced woonerf and designated a few parking lanes to have the drivers park in designated places, which is the requirement for woonerven stipulated in the Polish highway code [9]. Taking this into consideration, in the current research the test stations were sited at the beginning or at the end of the parking lanes, while using the existing signposts for mounting the automatic measuring systems. On the western part of the street, opposite the hospital premises, there are five detached two-storey single-family buildings that are served by parking places situated in each of the respective properties (Figure 7a). On the eastern part of this street, there are three single-family buildings, also being served by parking for residents located within the property limits (Figure 7c). Several visits were paid to the site to confirm that the parking lanes PL constructed beyond the carriageway near the centre of the clinic and hospital do not satisfy the demand for parking, and the drivers park their cars illegally as a result (Figure $7 \mathrm{~b}$ ). This concerned, in particular, the area in the vicinity of the entrances to the clinic, i.e., on the section between the test stations P4 and P6. From the hospital premises, there are four emergency exits to the analysed street, which are normally closed to traffic. The parking lanes are solely marked by line markings and they have different end treatments (skew or rectangular). In line with woonerf scheme principles, there are no pedestrian crossings over the whole length of the street and a kerb separated walkway runs only along the hospital premises. There is also a short walkway on the other side of the street (Figure 7a), running along the five residential buildings and ending right after the test station P2. 


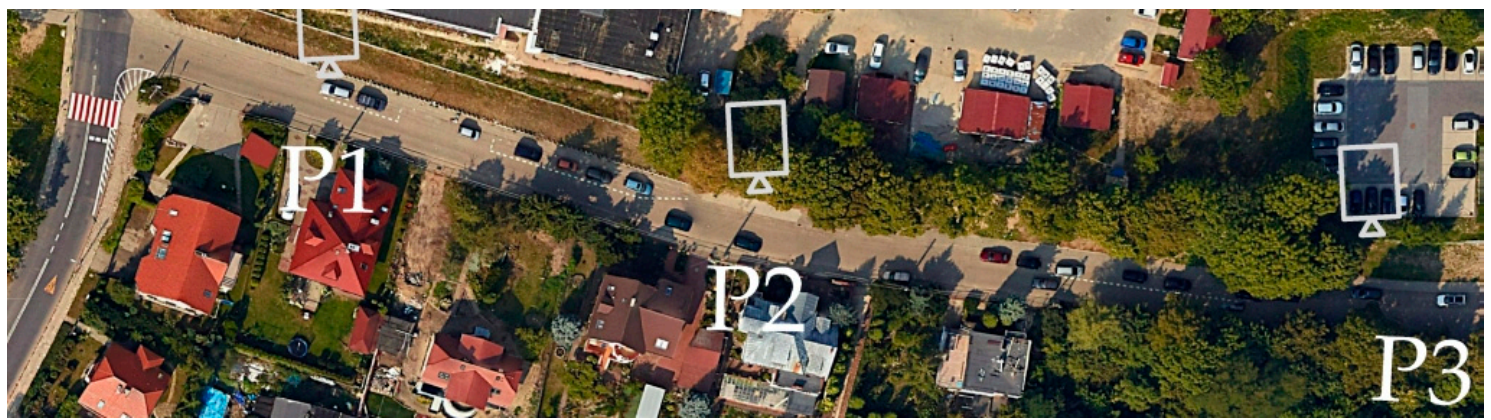

(a)

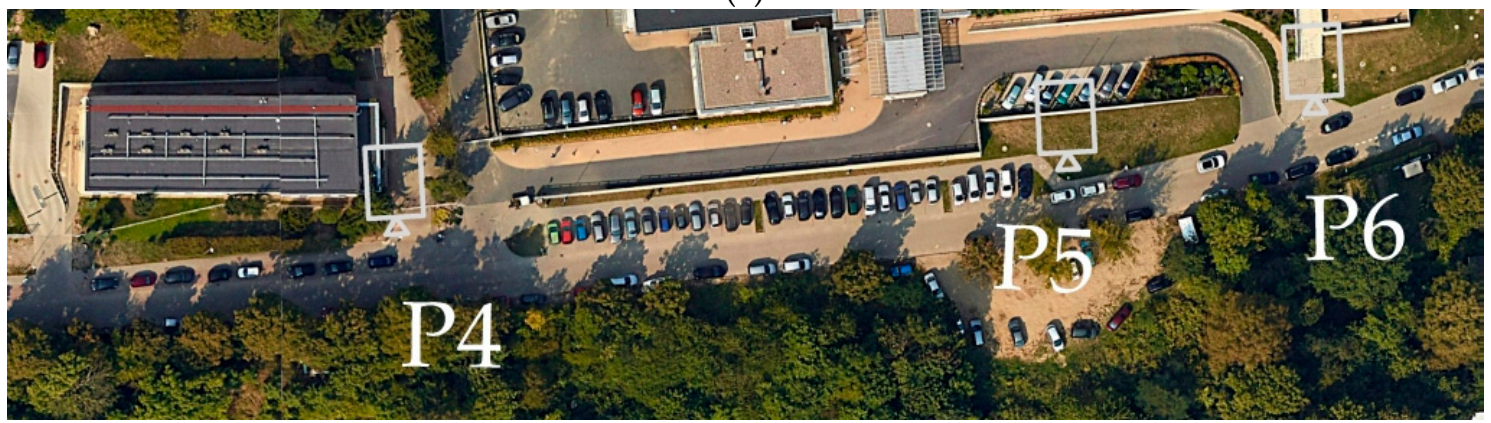

(b)

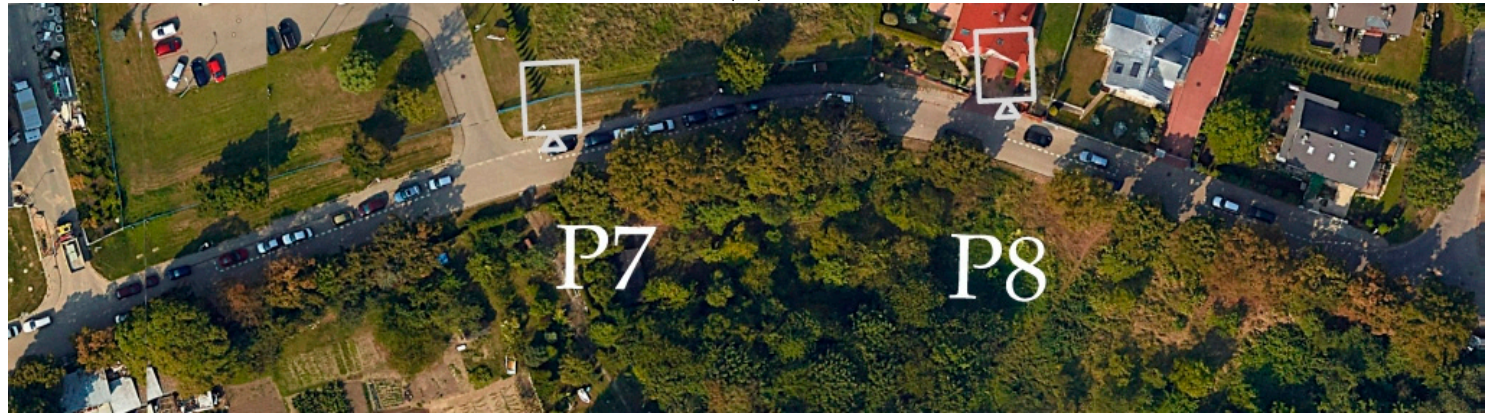

(c)

Figure 7. Arrangement of parking lanes PL and test stations $\mathrm{P}_{i}$ along the analysed street (drawn on the Google Earth map [20]): (a) Western section and test stations No. P1, P2, P3; (b) Middle section and test sections No. P4, P5, P6 located at the clinic entrances and gates; and, (c) Eastern section and test stations No. P7, P8.

The traffic volume and the speeds of free-flowing and continuous traffic flows were measured during the 24-hour traffic survey on weekdays. The weather was dry and such was the pavement surface. Three characteristic traffic volume ranges were recorded (Figure 8): $\leq 30 \mathrm{v} / \mathrm{h}, 30-50 \mathrm{v} / \mathrm{h}$ and higher, ca. $100 \mathrm{v} / \mathrm{h}$ on average. The 85 th percentile speed and the average speeds for the above-mentioned three traffic volume ranges were calculated based on the obtained measurement data. Table 2 presents the dimensions of parking lanes, distances between them, and their end treatments. Table 3 gives the basic traffic volume data and $v_{85}$ free-flow speeds for the respective traffic volume ranges. Although the street chosen for the analysis is not a typical woonerf street, as shown in Figure 1, above, with eight parking lanes of different lengths and spacing distances it can well be used for investigating the effect of the parking lane configuration on the vehicle speeds (Table 2). 


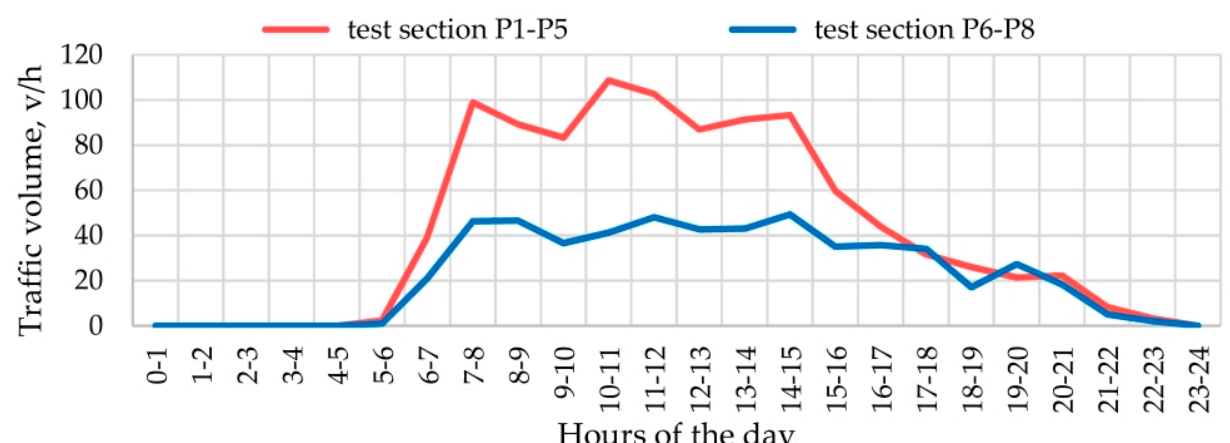

Figure 8. Distribution of hourly traffic volume on the tested sections throughout the day.

Table 2. Parameters of the analysed parking lanes PL.

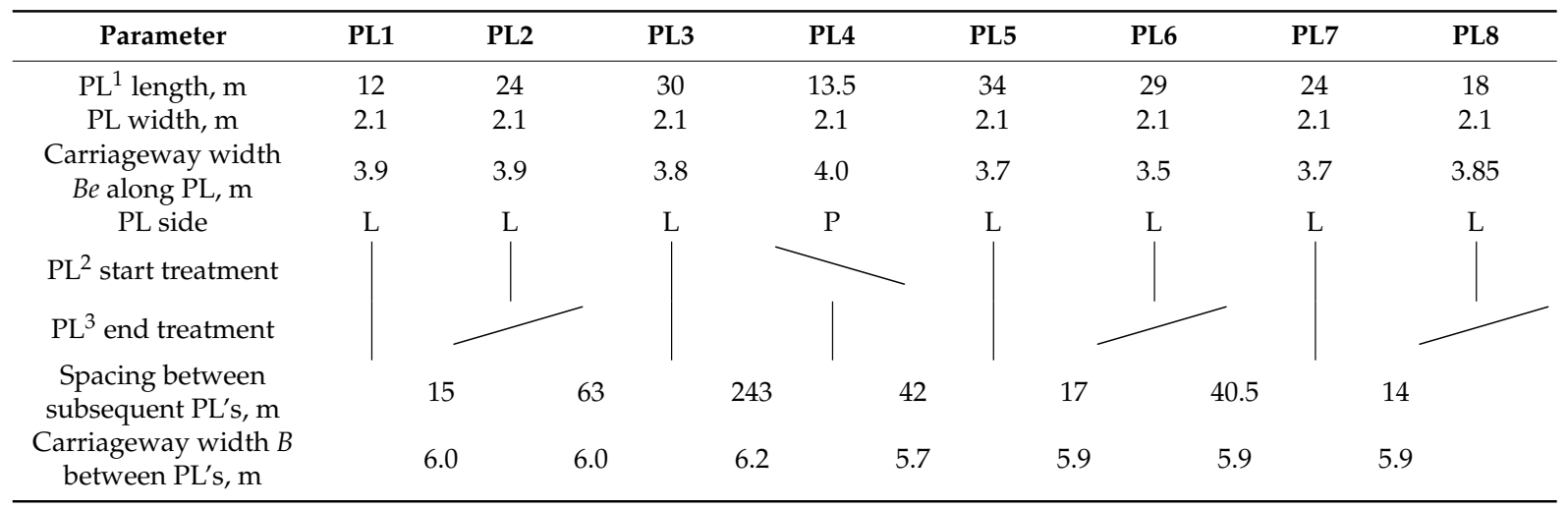

${ }^{1} \mathrm{PL}$ - parking lane. ${ }^{2}$ Graphical symbol representing rectangular or skew parking lane start treatment. ${ }^{3}$ Graphical symbol representing rectangular or skew parking lane end treatment.

Table 3. Values of the main traffic parameters obtained on the respective test stations $\mathrm{P}_{i}$.

\begin{tabular}{|c|c|c|c|c|c|c|c|c|}
\hline Parameter & $\mathbf{P 1}^{1}$ & $\mathbf{P 2}$ & P3 & $\mathbf{P 4}$ & P5 & P6 & P7 & P8 \\
\hline \multicolumn{9}{|c|}{ Traffic: } \\
\hline $\begin{array}{l}\text { ca. } 100 \mathrm{v} / \mathrm{h} \\
30-50 \mathrm{v} / \mathrm{h}\end{array}$ & $\begin{array}{l}+^{2} \\
+\end{array}$ & $\begin{array}{l}+ \\
+\end{array}$ & $\begin{array}{l}+ \\
+\end{array}$ & $\begin{array}{l}+ \\
+\end{array}$ & $\begin{array}{l}+ \\
+\end{array}$ & $\begin{array}{l}-3 \\
+\end{array}$ & $\begin{array}{l}- \\
+\end{array}$ & $\begin{array}{c}- \\
+\end{array}$ \\
\hline$\leq 30 \mathrm{v} / \mathrm{h}$ & + & + & + & + & + & + & + & + \\
\hline \multicolumn{9}{|c|}{ Traffic direction $(\mathrm{A}-\mathrm{B}) \longrightarrow$} \\
\hline \multicolumn{9}{|c|}{$85^{\text {th }}$ percentile speed of free-flowing traffic $v_{85}, \mathrm{~km} / \mathrm{h}$} \\
\hline ca. $100 \mathrm{v} / \mathrm{h}$ & 35.0 & 32.0 & 28.0 & 41.0 & 37.0 & - & - & - \\
\hline $30-50 \mathrm{v} / \mathrm{h}$ & 35.0 & 36.5 & 33.0 & 52.0 & 37.0 & 40.0 & 45.0 & 42.5 \\
\hline$\leq 30 \mathrm{v} / \mathrm{h}$ & 35.1 & 38.0 & 33.2 & 54.0 & 44.1 & 50.6 & 44.0 & 42.5 \\
\hline \multicolumn{9}{|c|}{ Average speed $v_{a}, \mathrm{~km} / \mathrm{h}$} \\
\hline ca. $100 \mathrm{v} / \mathrm{h}$ & 27.6 & 25.9 & 22.0 & 29.5 & 27.5 & - & - & - \\
\hline $30-50 \mathrm{v} / \mathrm{h}$ & 27.9 & 28.1 & 24.4 & 35.8 & 27.4 & 29.1 & 34.7 & 33.6 \\
\hline$\leq 30 \mathrm{v} / \mathrm{h}$ & 27.1 & 28.9 & 25.6 & 41.0 & 35.6 & 40.6 & 36.8 & 33.6 \\
\hline \multicolumn{9}{|c|}{1 Traffic direction (B-A) } \\
\hline \multicolumn{9}{|c|}{$85^{\text {th }}$ percentile speed of free-flowing traffic $v_{85}, \mathrm{~km} / \mathrm{h}$} \\
\hline са. $100 \mathrm{v} / \mathrm{h}$ & 33.5 & 34.0 & 27.0 & 42.0 & 40.0 & - & - & - \\
\hline $30-50 \mathrm{v} / \mathrm{h}$ & 35.0 & 36.0 & 29.7 & 55.0 & 39.0 & 43.0 & 40.0 & 37.0 \\
\hline$\leq 30 \mathrm{v} / \mathrm{h}$ & 36.1 & 39.3 & 31.0 & 51.2 & 43.8 & 45.5 & 36.6 & 35.0 \\
\hline \multicolumn{9}{|c|}{ Average speed $v_{a}, \mathrm{~km} / \mathrm{h}$} \\
\hline ca. $100 \mathrm{v} / \mathrm{h}$ & 26.7 & 28.0 & 21.2 & 30.4 & 32.0 & - & - & - \\
\hline $30-50 \mathrm{v} / \mathrm{h}$ & 28.3 & 29.8 & 23.6 & 37.2 & 30.2 & 32.4 & 33.2 & 30.9 \\
\hline$\leq 30 \mathrm{v} / \mathrm{h}$ & 26.1 & 31.5 & 25.5 & 37.8 & 36.3 & 34.7 & 29.2 & 28.5 \\
\hline
\end{tabular}

${ }^{1} \mathrm{P}_{i}$ - test station. ${ }^{2}$ Plus sign (+) - means the traffic volume confirmed by measurements. ${ }^{3}$ Minus sign (-) - means a lack of a given traffic volume in the measurements (arrows define the direction of traffic). 
For simultaneous measurement on the respective test station $\mathrm{P} 1, \mathrm{P} 2, \ldots \mathrm{P} n$, we used a set of synchronised SR4 electronic speed and traffic volume measuring systems equipped with automatic recording function [23]. The test station locations were chosen to serve the purpose of the study, that is near the parking lanes, where they are alternately located between the two sides or at changes in the carriageway width. The SR4 devices were mounted on the poles of the existing traffic signs, placed generally at the parking lane start or end.

All of the measurement data were subjected to statistical analysis, including a few significance and goodness-of-fit, independence and median tests to verify whether the vehicle speed depends on the road conditions in the immediate vicinity of the analysed test station (including parking lane location, carriageway narrowing size or length, etc.) and to verify the effect the length of the analysed parking lane or spacing between subsequent parking lanes on speed reduction.

The primary objective of woonerven is to calm the vehicular traffic and ensure safety of road users, pedestrians, in particular. There are several infrastructure elements that can be used to make the drivers slow down (see Section 1). The implementation of woonerf scheme is expected to result in improved safety of traffic, reduced vehicle speeds and less noise, air pollution, and exhaust emissions (Figure 9), with the improvement to parking arrangements and enhanced appearance being additional benefits. Vehicle speed reduction resulting from the implementation of various traffic calming measures is also important.

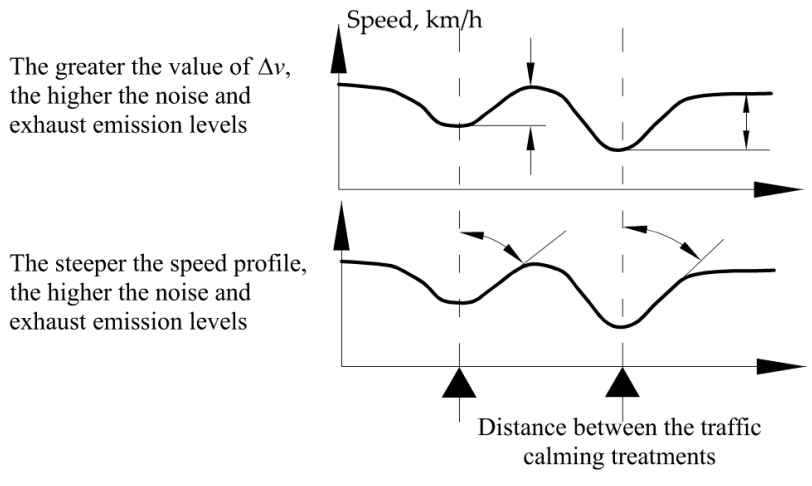

(a)

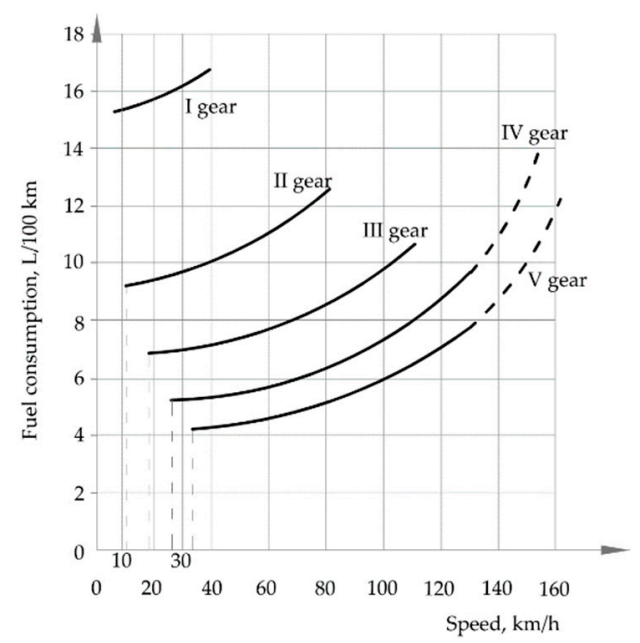

(b)

Figure 9. Interpretations of the noise, exhaust emission and fuel consumption levels depending on the vehicle speed: (a) Speed profile between the traffic calming treatments and level of noise and exhaust emissions (based on Swiss guidelines [24]); (b) Fuel consumption depending on the gear and speed (based on a French study [25]).

The guidelines used in different countries [10-17] list and describe various traffic calming measures recommended for woonerven and their speed-reducing effect is also given in some of them. Unfortunately, in many cities and smaller localities, these measures are limited to placing a woonerf traffic signs with or without parking lanes PL or parking spaces PP and traffic calming measures are used scarcely if at all. This is quite a common practice, especially in new housing developments, being intended to control speed and improve the safety of traffic. It must be noted that the above-mentioned national guidelines do not give specific design recommendations relating to such measures. Moreover, these measures are presently used not only in Poland. Therefore, we conducted a speed survey at eight test stations on a chosen street (Figure 7), where the parking lanes PL are solely identified by pavement markings without any further traffic calming measures used within the woonerf limits.

Moreover, taking account of the recommendations and information given in $[24,25]$ and based on the speed data that were obtained on the subsequent test stations, the authors identified places 
with the greatest fuel consumption, air pollution, and noise emission levels caused by rapid acceleration/ deceleration.

\section{Results}

\subsection{Analysis of the Confidence Intervals}

As the first step, the data were subjected to the most fundamental goodness-of-fit Pearson's and Kolmogorov's tests, followed by consistency tests to detect any gross errors in relation to outliers. These analyses were carried for three different hourly traffic volume ranges. The results of the above-mentioned statistical tests confirmed the null hypothesis, i.e., the assumption of normal distribution of the vehicle speed and a lack of outliers. Standard confidence interval calculations were carried out as the next step, whose results are presented in Figure 10, below.

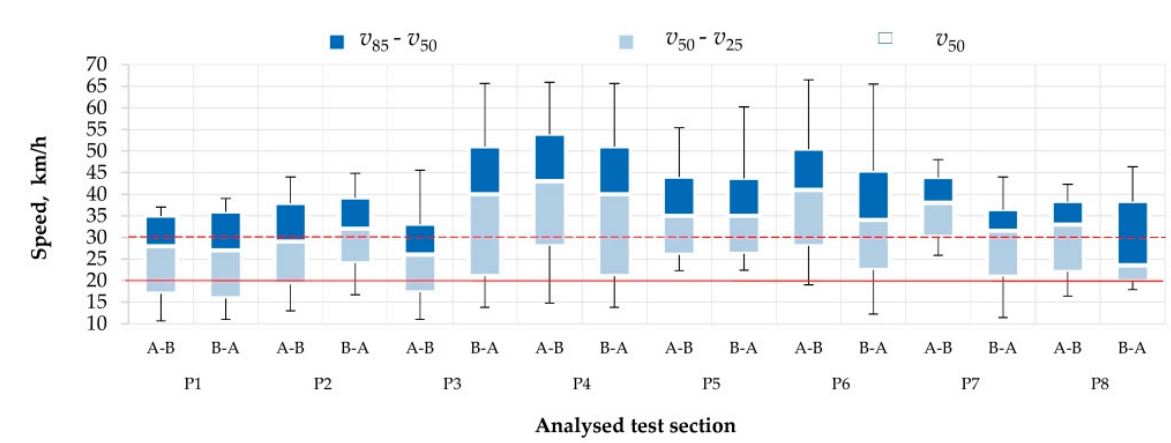

(a)

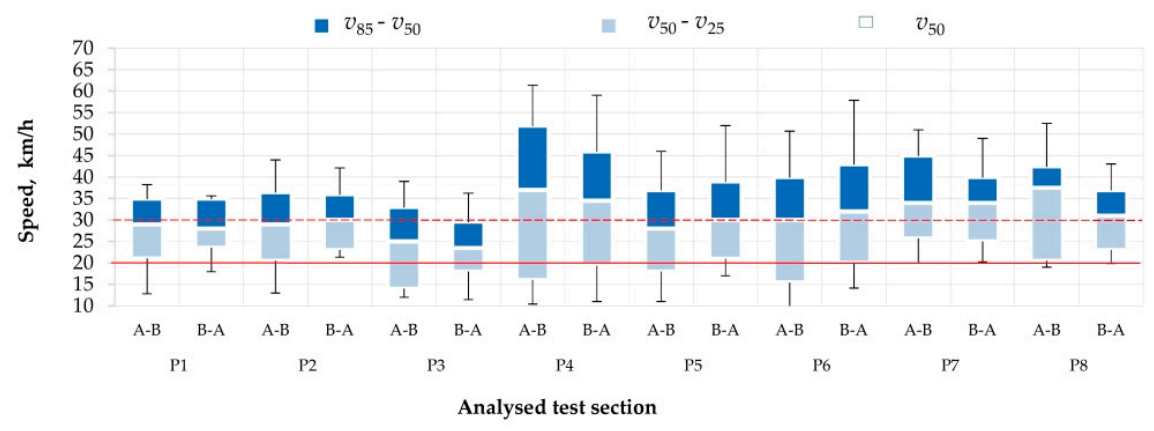

(b)

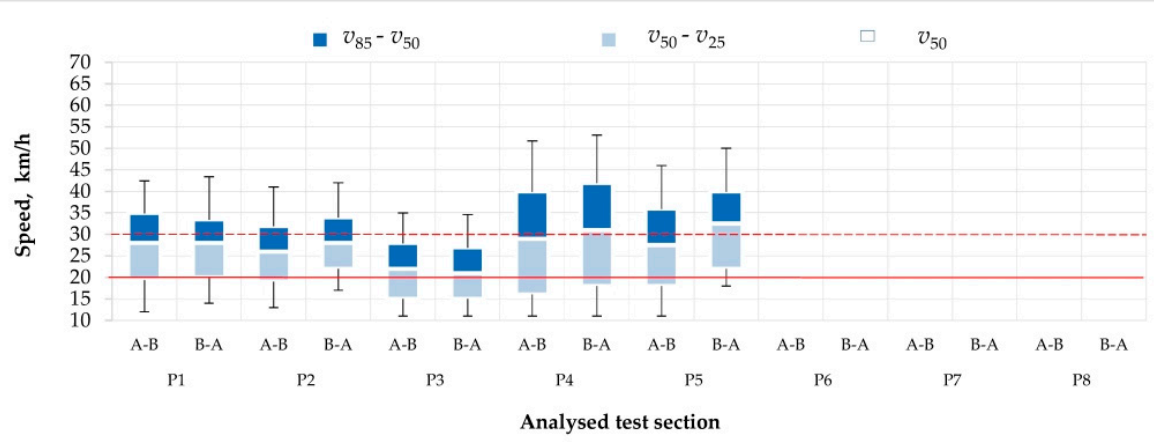

(c)

Figure 10. Distribution of speed parameters on the test sections by percentile speed range: $v_{85}-v_{50}$ and $v_{50}-v_{25}$ for traffic volume ranges of $(\mathbf{a}) \leq 30 \mathrm{v} / \mathrm{h} ;(\mathbf{b}) 30-50 \mathrm{v} / \mathrm{h}$; and, (c) ca. $100 \mathrm{v} / \mathrm{h}$. (A-B west to east, B-A east to west). 
The analysis of the data that are presented in Figure 10 showed that the vehicle speed increases with the decreasing volume of traffic and the speed distribution parameters were at a similar level at all the test stations in both directions of traffic. The greatest speed differences in both directions of traffic were noted at the lowest traffic volume level. The highest speeds were noted at the test stations $\mathrm{P} 4$ and on the section between P4-P6 test stations. However, the woonerf speed requirement of $v_{85} \leq 20 \mathrm{~km} / \mathrm{h}$ (solid red line in Figure 10) was not met on any of the test sections. As we can read in the comments regarding the traffic conditions in $[11-13,15]$ drivers tend to exceed the speed limit binding in woonerven by ca. $10 \mathrm{~km} / \mathrm{h}$. That being sad, from the data that are presented in Figure 6, we see that, on the street under analysis, only in a few cases the $85^{\text {th }}$ percentile speed was below $30 \mathrm{~km} / \mathrm{h}$ (dashed red line in Figure 10). These data confirm that, most probably, the drivers were not aware of the woonerf speed limit of $20 \mathrm{~km} / \mathrm{h}$, or they were demotivated by a lack of any traffic calming measures other than parking lane, which, however, were solely identified by pavement markings. Small traffic density encouraged faster driving, as evidenced by the data that are presented in Figure 10.

Considering the above results that were obtained on a typical woonerf-type street, we should agree with the comments given in $[11,13,26,27]$, which postulate placement of an additional speed limit sign on the standard woonerf entry signboard (Figure 11). More importantly, they call for the placement of additional vertical traffic calming measures at the start and end of each parking lane PL to advise the drivers of the narrowing, i.e., to influence their perception at times where there are no cars parked there.

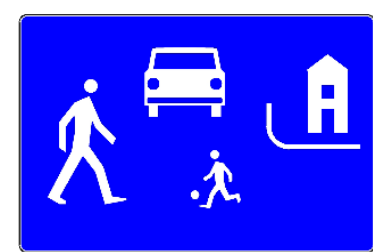

(a)

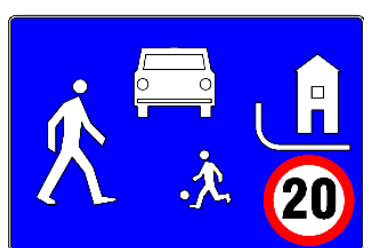

(b)

Figure 11. Woonerf sign face: (a) Currently used in most countries including Poland; and, (b) Sign face including the speed limit sign, as recommended in $[11,13,26,27]$.

\subsection{The Results of Statistical Tests Confirming the Effect of the Traffic Volume on the Vehicle Speed}

It was necessary to verify whether the speed data obtained at the deployed test stations depend on the varying traffic density, the rate of traffic flow in a given direction, and the test station location as well since the chosen woonerf-type street includes eight parking lanes PL, being solely identified by pavement marking lines, which reduce the two-way road to one travel lane, accompanied by two parking areas located beyond the carriageway (Figure 7). This section investigates whether speed distribution depends on the traffic volume variations.

In some cases, the significance test could not be done for two average values due to the negative result of the test of equality of variances for both the test stations in consideration, being due to excessive variation of the standard deviation. The independence and median tests were chosen for further statistical inference while taking this into account.

As the first step, independence and median tests were carried out for three different hourly traffic volumes (data sets $X, Y$, and $Z$ ) to verify whether the tested speed distributions are independent of the traffic volume, i.e., whether the equality of events described by following equation holds true:

$$
P(X \cap Y \cap Z)=P(X) \cdot P(Y) \cdot P(Z)
$$

or braking down into three traffic volume ranges is required for the purpose of further analyses due to the significance level of difference between them (hypotheses (2) and (3) refer). Table 4 presents the results of the statistical analyses performed in this respect. The independence tests was done twice, the first time for the woonerf speed limit of $20 \mathrm{~km} / \mathrm{h}$, and the second time for the speed limit of $30 \mathrm{~km} / \mathrm{h}$, 
while taking the speed data compiled in Table 3 and presented in Figure 10 into account. Thus, with three traffic volume levels, it was possible to develop a 2-by-3 contingency table of the observed and expected values $\left(\chi_{\alpha}{ }^{2}=5.99, \alpha=0.05\right)$ in accordance with the independence test procedure. Where only two volume ranges were confirmed, a 2-by-2 contingency table of the observed and expected values was used $\left(\chi_{\alpha}^{2}=3.84, \alpha=0.05\right)$. The median test, in turn, was carried out twice in relation to the speed distributions for two comparable traffic volume ranges:

$\leq 30 \mathrm{v} / \mathrm{h}$ and $30-50 \mathrm{v} / \mathrm{h}$ as the first one and $30-50 \mathrm{v} / \mathrm{h}$ and ca. $100 \mathrm{v} / \mathrm{h}$ as the second one, in each time determining the median value of the two compared sets. In accordance with the median test principles, a 2-by-2 contingency table of observed and expected values was created and used in the test.

Independence test $\chi^{2}$

$H_{0}: P\left\{X=x_{i}, Y=y_{i}, Z=z_{i}\right\}=P\left\{X=x_{i}\right\} P\left\{Y=y_{i}\right\} P\left\{Z=z_{i}\right\}$ —"vehicle speed populations grouped in three sets $X, Y$, and $Z$ are independent of the volume of traffic",

$H_{1}: P\left\{X=x_{i}, Y=y_{i}, Z=z_{i}\right\} \neq P\left\{X=x_{i}\right\} P\left\{Y=y_{i}\right\} P\left\{Z=z_{i}\right\}$-"vehicle speed populations grouped in three sets $X, Y$, and $Z$ are not independent of the volume of traffic".

Vehicle speed populations: $P(X)$-at traffic volume of $\leq 30 \mathrm{v} / \mathrm{h} ; P(Y)$ —at traffic volume of 30-50 $\mathrm{v} / \mathrm{h} ; P(Z)$-at traffic volume of ca. $100 \mathrm{v} / \mathrm{h} ; x_{i}, y_{i}$, and $z_{i}$-are single speeds measured at the respective traffic volume levels, $\mathrm{km} / \mathrm{h}$.

Median test $\chi^{2}$

$H_{0}: F_{1}(x)=F_{2}(x)$ - "vehicle speed distributions are independent of the volume of traffic",

$H_{1}: F_{1}(x) \neq F_{2}(x)$ - "vehicle speed distributions are not independent of the volume of traffic"

and

$H_{0}: F_{2}(x)=F_{3}(x)$-"vehicle speed distributions are independent of the volume of traffic",

$H_{1}: F_{2}(x) \neq F_{3}(x)$ - "vehicle speed distributions are not independent of the volume of traffic".

Vehicle speed cumulative density functions: $F_{1}(x)$-for traffic volume of $\leq 30 \mathrm{v} / \mathrm{h} ; F_{2}(x)$-for traffic volume of $30-50 \mathrm{v} / \mathrm{h} ; F_{3}(x)$-for traffic volume of ca. $100 \mathrm{v} / \mathrm{h}$.

Table 4. The results of independence and median tests of vehicle speed populations for three traffic volumes in both directions of traffic $(\alpha=0.05)$.

\begin{tabular}{|c|c|c|c|c|c|c|c|c|}
\hline Type of test & P1 & $\mathbf{P} 2$ & P3 & $\mathbf{P 4}$ & P5 & P6 & P7 & P8 \\
\hline \multicolumn{9}{|c|}{ Traffic direction $(\mathrm{A}-\mathrm{B}) \longrightarrow$} \\
\hline Independence test $\chi^{21}$ & 0.32 & 0.67 & 3.59 & 5.66 & $8.10^{6}$ & 6.23 & 0.48 & 0.20 \\
\hline Independence test $\chi^{22}$ & 0.12 & 20.59 & 26.79 & 21.64 & 15.68 & 19.66 & 5.87 & 3.80 \\
\hline$\chi_{\alpha}^{2}=$ & 5.99 & 5.99 & 5.99 & 5.99 & 5.99 & 3.84 & 3.84 & 3.84 \\
\hline Median test $\chi^{23}$ & 0.04 & 0.37 & 0.44 & 4.09 & 11.77 & 27.42 & 6.28 & 2.70 \\
\hline Median test $\chi^{24}$ & 0.11 & 10.05 & 10.35 & 13.87 & 0.48 & -5 & - & - \\
\hline$\chi_{\alpha}^{2}=$ & 3.84 & 3.84 & 3.84 & 3.84 & 3.84 & 3.84 & 3.84 & 3.84 \\
\hline \multicolumn{9}{|c|}{ Traffic direction $(\mathrm{B}-\mathrm{A})$} \\
\hline Independence test $\chi^{21}$ & 2.20 & 1.37 & 9.27 & 2.30 & 4.54 & 0.38 & 4.16 & 1.24 \\
\hline Independence test $\chi^{22}$ & 1.63 & 14.33 & 11.15 & 5.21 & 12.38 & 0.85 & 2.37 & 0.75 \\
\hline$\chi_{\alpha}^{2}=$ & 5.99 & 5.99 & 5.99 & 5.99 & 5.99 & 3.84 & 3.84 & 3.84 \\
\hline Median test $\chi^{23}$ & 0.03 & 3.14 & 4.50 & 0.71 & 13.42 & 1.36 & 4.53 & 0.59 \\
\hline Median test $\chi^{24}$ & 0.34 & 3.67 & 6.61 & 3.07 & 6.99 & - & - & - \\
\hline$\chi_{\alpha}^{2}=$ & 3.84 & 3.84 & 3.84 & 3.84 & 3.84 & 3.84 & 3.84 & 3.84 \\
\hline
\end{tabular}

${ }^{1}$ Independence test assuming that the sets of vehicle speeds are analysed in the following two groups: $\leq 20 \mathrm{~km} / \mathrm{h}$ and $>20 \mathrm{~km} / \mathrm{h} .{ }^{2}$ Independence test assuming that the sets of speed are analysed in the following two groups: $\leq 30 \mathrm{~km} / \mathrm{h}$ and $>30 \mathrm{~km} / \mathrm{h} .{ }^{3}$ Median test of cumulative density functions $F_{1}(x)$ and $F_{2}(x) .{ }^{4}$ Median test of cumulative density functions $F_{2}(x)$ and $F_{3}(x) .{ }^{5}(-)$ means that traffic volumes of ca. $100 \mathrm{v} / \mathrm{h}$ was not observed during the survey.

${ }^{6}$ The results which confirm the effect of the traffic volume on the vehicle speed are highlighted in bold. 
The results of the independency and median tests that are compiled in Table 4 show non-uniform variation of the vehicle speed distributions in relation to the traffic volume level and, as such, do not definitely confirm either of the tested hypotheses. Therefore, it is not possible to definitely confirm the dependency of the vehicle speed distributions and the traffic volume levels on the basis of the above-described statistical analysis.

\subsection{Results of Statistical Tests Confirming the Effect of the Direction of Traffic on the Vehicle Speed}

With the highly non-uniform results of the independence and median tests presented in Table 4 failing to determine whether the vehicle speeds depend on the traffic volume, a subsequent analysis was carried out for each test section with the results grouped in three traffic volume ranges in relation to vehicle speed distributions, this time being jointly considered for the two directions of traffic (according to hypotheses (4) and (5)) to check whether the speeds of traffic in the opposite directions can be considered jointly in further analyses. Table 5 presents the results of these tests. In this case, in all of the tests, in accordance with the assumption to analyse the traffic in both directions, 2-by-2 tables of observed and expected values were built $\left(\chi_{\alpha}^{2}=3.84, \alpha=0.05\right)$.

Independence test $\chi^{2}$ - the null hypothesis $H_{0}$ is tested to answer the question of whether the vehicle speed distributions are independent of the direction of traffic, the alternative hypothesis $H_{1}$ claiming that the speed distributions are not independent of,. i.e., they are related to the direction of traffic:

$$
\begin{array}{ccc}
H_{0}: P\left\{X=x_{i}\right\}^{\mathrm{A}-\mathrm{B}}=P\left\{X=x_{i}\right\}^{\mathrm{B}-\mathrm{A}} & H_{0}: P\left\{Y=y_{i}\right\}^{\mathrm{A}-\mathrm{B}}=P\left\{Y=y_{i}\right\}^{\mathrm{B}-\mathrm{A}} & H_{0}: P\left\{Z=z_{i}\right\}^{\mathrm{A}-\mathrm{B}}=P\left\{Z=z_{i}\right\}^{\mathrm{B}-\mathrm{A}} \\
H_{1}: P\left\{X=x_{i}\right\}^{\mathrm{A}-\mathrm{B}} \neq P\left\{X=x_{i}\right\}^{\mathrm{B}-\mathrm{A}} & H_{1}: P\left\{Y=y_{i}\right\}^{\mathrm{A}-\mathrm{B}} \neq P\left\{Y=y_{i}\right\}^{\mathrm{B}-\mathrm{A}} & H_{1}: P\left\{\mathrm{Z}=z_{i}\right\}^{\mathrm{A}-\mathrm{B}} \neq P\left\{Z=z_{i}\right\}^{\mathrm{B}-\mathrm{A}}
\end{array}
$$

Vehicle speed populations: $P(X)$-at traffic volume $\leq 30 \mathrm{v} / \mathrm{h} ; P(Y)$ 一at traffic volume of 30-50 v/h; $P(Z)$-at traffic volume of ca. $100 \mathrm{v} / \mathrm{h}$. Traffic directions: A-B and B-A.

Median test $\chi^{2}$-the null hypothesis $H_{0}$ is tested to answer the question of whether the vehicle speed cumulative density functions are independent of the direction of traffic, the alternative hypothesis $H_{1}$ claiming that the cumulative density functions are not independent of, i.e., are related to the direction of traffic:

$$
\begin{array}{lll}
H_{0}: F_{1}(x)^{\mathrm{A}-\mathrm{B}}=F_{1}(x)^{\mathrm{B}-\mathrm{A}} & H_{0}: F_{2}(x)^{\mathrm{A}-\mathrm{B}}=F_{2}(x)^{\mathrm{B}-\mathrm{A}} & H_{0}: F_{3}(x)^{\mathrm{A}-\mathrm{B}}=F_{3}(x)^{\mathrm{B}-\mathrm{A}} \\
H_{1}: F_{1}(x)^{\mathrm{A}-\mathrm{B}} \neq F_{1}(x)^{\mathrm{B}-\mathrm{A}} & H_{1}: F_{2}(x)^{\mathrm{A}-\mathrm{B}} \neq F_{2}(x)^{\mathrm{B}-\mathrm{A}} & H_{1}: F_{3}(x)^{\mathrm{A}-\mathrm{B}} \neq F_{3}(x)^{\mathrm{B}-\mathrm{A}}
\end{array}
$$

Cumulative distribution functions: $F_{1}(x)-$ for traffic volume of $\leq 30 \mathrm{v} / \mathrm{h} ; F_{2}(x)$-for traffic volume of 30-50 v/h; $F_{3}(x)$-for traffic volume of ca. $100 \mathrm{v} / \mathrm{h}$. Traffic directions A-B and B-A.

\begin{tabular}{|c|c|c|c|c|c|c|c|c|}
\hline Test type & P1 & $\mathbf{P 2}$ & P3 & $\mathbf{P 4}$ & P5 & P6 & P7 & P8 \\
\hline \multicolumn{9}{|c|}{ Traffic volume range of $\leq 30 \mathrm{v} / \mathrm{h}$ in both directions } \\
\hline Independence test $\chi^{2}$ & 1.70 & 2.91 & 1.62 & 1.15 & 0.08 & 2.60 & $8.46^{1}$ & 4.89 \\
\hline Median test $\chi^{2}$ & 0.00 & 1.93 & 0.02 & 1.01 & 0.03 & 3.71 & 14.01 & 6.95 \\
\hline \multicolumn{9}{|c|}{ Traffic volume range of $30-50 \mathrm{v} / \mathrm{h}$ in both directions } \\
\hline Independence test $\chi^{2}$ & 0.02 & 0.84 & 3.65 & 0.07 & 4.02 & 1.60 & 0.23 & 0,21 \\
\hline Median test $\chi^{2}$ & 0.10 & 1.84 & 1.49 & 1.50 & 3.22 & 1.51 & 0.01 & 0.33 \\
\hline \multicolumn{9}{|c|}{ Traffic volume of ca. $100 \mathrm{v} / \mathrm{h}$ in both directions } \\
\hline Independence test $\chi^{2}$ & 4.73 & 15.81 & 0.10 & 5.47 & 5.04 & -2 & - & - \\
\hline Median test $\chi^{2}$ & 3.25 & 18.68 & 1.68 & 5.47 & 1.50 & - & - & - \\
\hline
\end{tabular}

Table 5. Results of independence and median tests of vehicle speed data considered jointly for both direction of traffic broken down into three traffic volume ranges. The critical value for all the analysis is $\chi_{\alpha}^{2}=3.84$, for $\alpha=0.05$.

\footnotetext{
${ }^{1}$ The results which confirm the effect of the traffic volume on the vehicle speed distributions are highlighted in bold.
}

2 (-) traffic volume at the level of ca. $100 \mathrm{v} / \mathrm{h}$ was not observed on the section. 
While still not conclusive, the results that are given in Table 5 demonstrate non-uniform relationship between the speed distributions in both directions and the traffic volumes. At most test stations, the vehicle speed distributions are independent of the traffic direction for smaller traffic volumes $(\leq 30 \mathrm{v} / \mathrm{h}$ and 30-50 v/h). Conversely, at the traffic volume exceeding ca. $100 \mathrm{v} / \mathrm{h}$ at most test stations, the vehicle speed distributions are not independent of, i.e., are related to the direction of traffic.

\subsection{Results of Statistical Tests Confirming the Effect of the Carriageway Narrowing Location and Siting of the Parking Lanes on the Vehicle Speed}

While taking account of the above-mentioned statistical inference results, as presented in Sections 3.2 and 3.3, the authors decided to investigate whether the speed distributions depend on the siting of the carriageway narrowings and parking lanes PL along the street under analysis. Hence, the last steps of the process of statistical analysis were independence and median tests on a part of vehicle speed data obtained at the subsequent test stations, considered separately for the two directions of traffic, in order to answer the question of whether the speed distributions depend on the siting of parking lanes and carriageway narrowings (as per the hypotheses (6) and (7)). In this case, taking account of the output of statistical analyses, as given in Table 4, the sets of the observed vehicle speed values were not split by traffic volume range and the results that were obtained throughout the day were jointly considered. In the independence and median tests, the data were broken down into the traffic directions, since the lengths of approach to a given station were different from both directions (Figure 7). Additionally, the lengths of the carriageway narrowings at the respective test stations were different, the same as the arrangement of parking lanes PL on the two sides of the carriageway. Table 6 presents the results of the independence and median tests to test hypotheses (6) and (7). While considering the confidence intervals and the wide variation of the speed values, as presented in Figure 10, two tests for independence were carried out on the data split in populations, as follows: less or equal to $20 \mathrm{~km} / \mathrm{h}$ and over $20 \mathrm{~km} / \mathrm{h}$ and the other one less or equal $30 \mathrm{~km} / \mathrm{h}$ and over $30 \mathrm{~km} / \mathrm{h}$. Since all of the analyses consider two sets of vehicle speed values that were observed at the test stations $\mathrm{P}_{i}$ and $\mathrm{P}_{i+1}, 2$-by-2 contingency tables of the observed and expected values were built in allcases $\left(\chi_{\alpha}^{2}=3.84, \alpha=0.05\right)$.

Independence test $\chi^{2}$ of two vehicle speed populations at the subsequent test stations in one direction of traffic:

the null hypothesis $H_{0}: P\left\{\mathrm{P}_{i}=v_{i}, \mathrm{P}_{i+1}=v_{i+1}\right\}=P\left\{\mathrm{P}_{i}=v_{i}\right\} P\left\{\mathrm{P}_{i+1}=v_{i+1}\right\}$-"states that the vehicle speed populations are independent of the road narrowing location and the parking lanes arrangement",

the alternative hypothesis $H_{1}: P\left\{\mathrm{P}_{i}=v_{i}, \mathrm{P}_{i+1} \neq v_{i+1}\right\}=P\left\{\mathrm{P}_{i}=v_{i}\right\} P\left\{\mathrm{P}_{i+1}=v_{i+1}\right\}$-"claims that the vehicle speed populations are not independent of, i.e. are related to the road narrowing location and the parking lanes arrangement".

$P\left(\mathrm{P}_{i}\right)$ and $P\left(\mathrm{P}_{i+1}\right)$-vehicle speed populations at the subsequent test stations in one direction of traffic.

Median test $\chi^{2}$ of two vehicle speed populations at the subsequent test stations in one direction of traffic:

the null hypothesis $H_{0}: F_{i}(x)=F_{i+1}(x)$ - "claims that the vehicle speed cumulative density functions are independent of the road narrowing location and the parking lanes arrangement",

the null hypothesis $H_{1}: F_{i}(x) \neq F_{i+1}(x)$-"claims that the vehicle speed cumulative density functions are not independent of, i.e. are related to the road narrowing location and the parking lanes arrangement".

$F_{i}(x)$ and $F_{i+1}(x)$-vehicle speed cumulating density functions at the subsequent test stations in one direction of traffic. 
Table 6. Results of independence and median tests of vehicle speed data considered separately for the two direction of traffic at the subsequent test stations at $\chi_{\alpha}{ }^{2}=3.84, \alpha=0.05$.

\begin{tabular}{|c|c|c|c|c|c|c|c|}
\hline Test type & P1 \& P2 & P2 \& P3 & P3 \& P4 & P4 \& P5 & P5 \& P6 & P6 \& P7 & P7 \& P8 \\
\hline \multicolumn{8}{|c|}{ Traffic direction $(\mathrm{A}-\mathrm{B}) \longrightarrow$} \\
\hline Independence test $\chi^{21}$ & 0.29 & $159.03^{4}$ & 73.13 & 7.66 & 13.33 & 3.66 & 3.38 \\
\hline Independence test $\chi^{22}$ & 8.71 & 143.88 & 300.09 & 5.47 & 12.96 & 0.10 & 0.06 \\
\hline Median test $\chi^{23}$ & 6.15 & 193.96 & 194.25 & 4.66 & 12.48 & 2.93 & 0.54 \\
\hline \multicolumn{8}{|c|}{ Traffic direction $(\mathrm{B}-\mathrm{A})$} \\
\hline Independence test $\chi^{21}$ & 8.53 & 131.19 & 39.56 & 0.01 & 2.50 & 7.69 & 0.05 \\
\hline Independence test $\chi^{22}$ & 6.43 & 123.19 & 251.6 & 11.28 & 11.35 & 4.36 & 2.48 \\
\hline Median test $\chi^{23}$ & 7.35 & 147.62 & 132.20 & 11.13 & 11.35 & 0.97 & 2.09 \\
\hline
\end{tabular}

${ }^{1}$ Independence test of populations $F_{i}(x)$ and $F_{i+1}(x)$, with the population data split to $\leq 20 \mathrm{~km} / \mathrm{h}$ and $>20 \mathrm{~km} / \mathrm{h}$ sets

${ }^{2}$ Independence test of populations $F_{i}(x)$ and $F_{i+1}(x)$, with the population data split to $\leq 30 \mathrm{~km} / \mathrm{h}$ and $>30 \mathrm{~km} / \mathrm{h}$ sets.

${ }^{3}$ Median test of cumulative density functions $F_{i}\left(\leq v_{50}\right)$ and $F_{i+1}\left(>v_{50}\right)$ estimated at the subsequent test stations.

${ }^{4}$ The results that confirm the effect of the road narrowing location and the parking lanes arrangement on the vehicle speed distributions are highlighted in bold.

In almost all cases, the results of independence and median tests satisfy the inequality $\chi^{2} \geq \chi_{\alpha}{ }^{2}$ (Table 6), implying the rejection of null hypothesis $H_{0}$ claiming independence of the analysed variables, i.e., the vehicle speed distributions depended on the test location which is related to the road narrowing location and on arrangement of the parking lanes on both sides of the carriageway and, as such, they should not be jointly analysed along the road. The analysis of results of both the independence and median tests, as presented in Table 6, showed statistically significant differences between that the vehicle speed distributions in both directions of traffic in almost all analysed cases, with the exception of the last two test stations, i.e., the speed distributions are not independent of the siting of the carriageway narrowings and arrangement of parking lanes on the street under analysis. This hypothesis was confirmed for both divisions into vehicle speed populations: one less or equal to $20 \mathrm{~km} / \mathrm{h}$ and over $20 \mathrm{~km} / \mathrm{h}$ and the other one less or equal $30 \mathrm{~km} / \mathrm{h}$ and over $30 \mathrm{~km} / \mathrm{h}$.

\subsection{The Results of Speed Profile Analysis along the Analysed Street and Identification of Sections under the Greatest Impact of Noise, Pollution and Exhaust Gas Emissions}

Taking the statistical inference results into account, in further analyses we considered the speed distribution parameters grouped by three traffic volume ranges and two directions of traffic (Figure 12). The analysis of the data that are presented in Figure 8 showed that the speeds are different, depending on the direction of traffic yet with similar speed profiles, i.e., similar differences in the variation of the $85^{\text {th }}$ percentile speed $v_{85}$ at the same test stations. Large differences in the $85^{\text {th }}$ percentile speed values were observed on the P3-P6 section, where the carriageway has its full width of $6.1 \mathrm{~m}$ and parking places are located beyond the carriageway limits (Figures $7 \mathrm{~b}$ and 12). Another peculiarity noted in the analysis are the differences in speeds at which the drivers enter the woonerf area from both ends of the analysed street. 


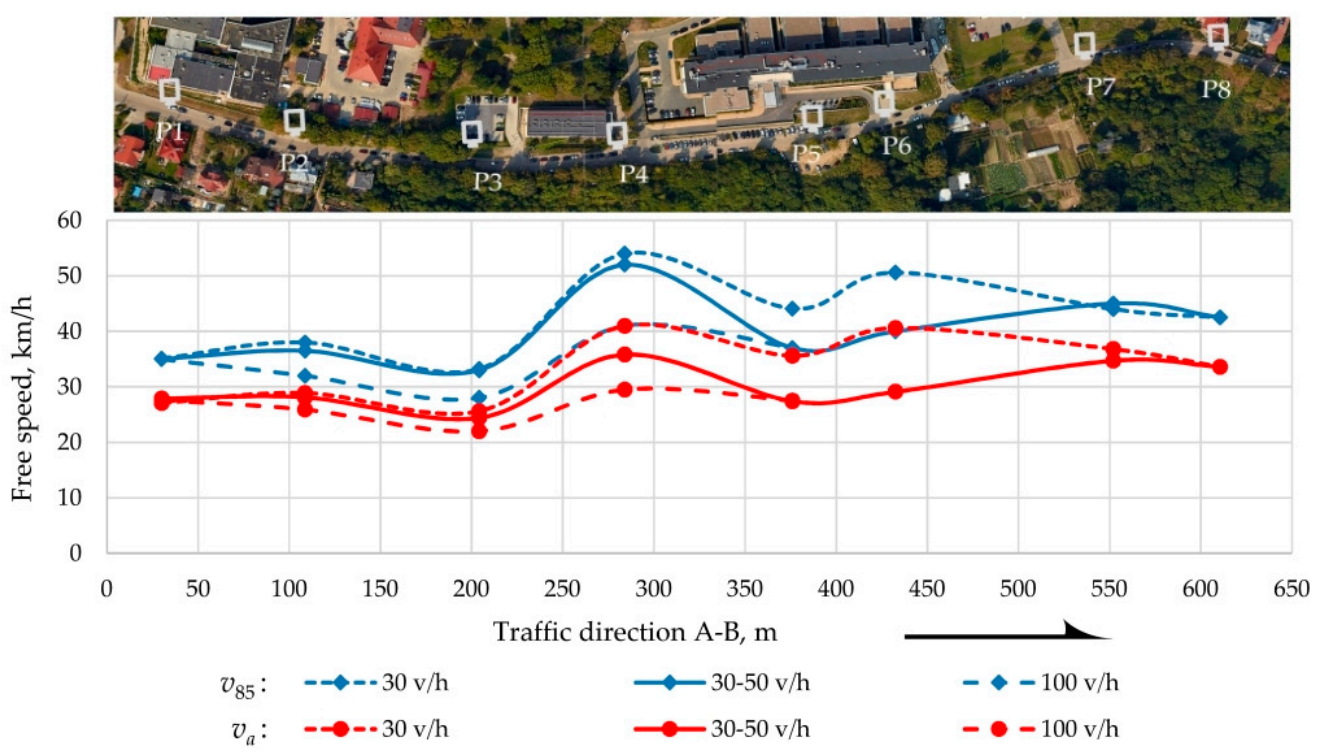

(a)

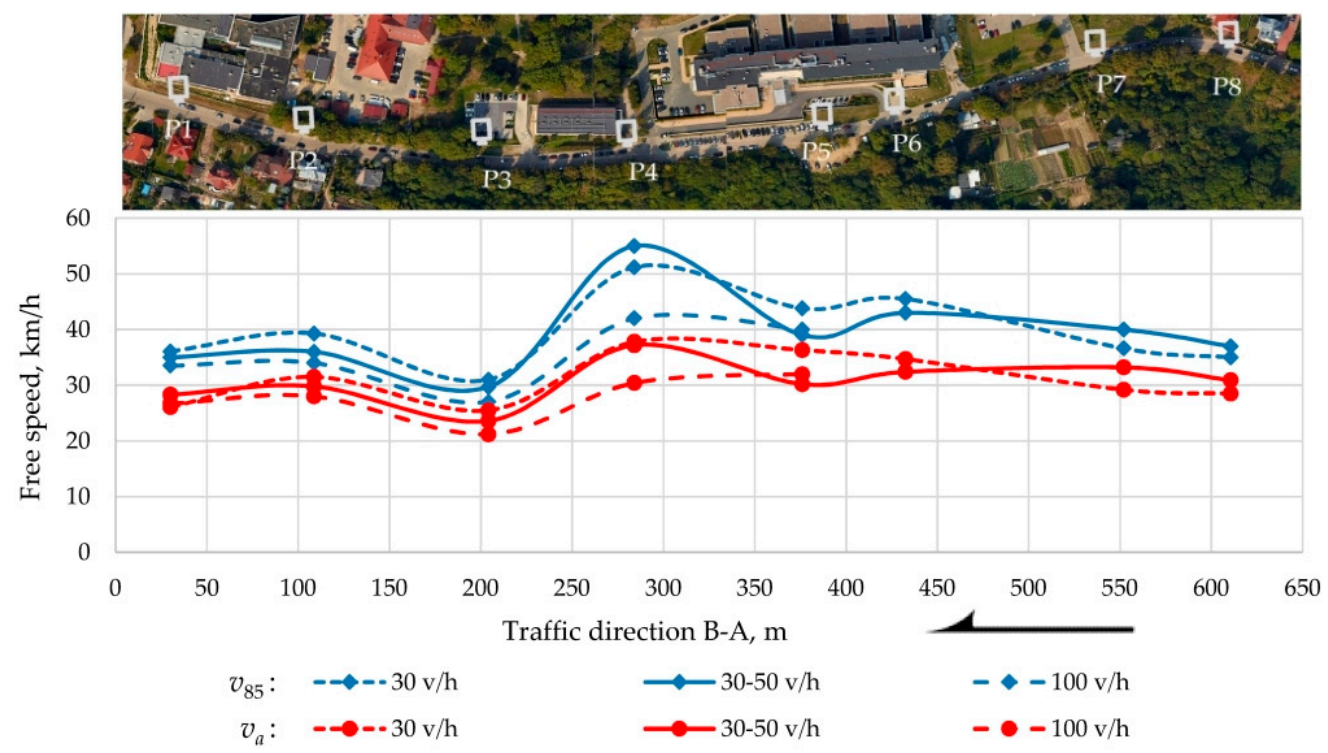

(b)

Figure 12. Speed distribution parameters of free-flowing traffic along the analysed street: (a) Traffic direction A-B; (b) Traffic direction B-A.

The greatest differences of the $85^{\text {th }}$ percentile speed $\Delta v_{85}$ for both directions of traffic were observed near the entrances to the cancer clinic, i.e., where the carriageway widens to the maximum width of $6.1 \mathrm{~m}$, encouraging driving at greater speeds, according to the speed profiles that are presented in Figure 12. The problem of illegal parking and blocking of allotment entrances was found to persist, which were the main causes of woonerf scheme implementation by the city administration (including designation of parking spaces and imposing the $20 \mathrm{~km} / \mathrm{h}$ speed limit). The greatest noise, air pollution, and exhaust emissions were noted on the section between P3 and P6 test stations (in comparison to the test data from other test stations), where the differences of $85^{\text {th }}$ percentile speed $\Delta v_{85}$ are in the range of $10-20 \mathrm{~km} / \mathrm{h}$ with a very steep speed profile. Note that, according to the Swiss guidelines [24], as presented in Figure 9a, one should tend to obtain the values of $\Delta v_{85}$ as small as possible in the 
subsequent sections of the street. This being so, the worst situation from the healthy environment viewpoint is encountered at the entry to the clinic building, i.e., right where ensuring calm and encouraging conditions would be desired. Taking the exhaust emission analyses presented in [28-30] into account, in particular relating to the two speed ranges of $30 \mathrm{~km} / \mathrm{h}$ and $50 \mathrm{~km} / \mathrm{h}$, as is the case in [30], we can consider the implementation of woonerf design unsuccessful in the street under analysis. The $6.1 \mathrm{~m}$ wide by $250 \mathrm{~m}$ long carriageway section remaining in the central portion of the street (specifically between the test stations P3 and P6), preceded and followed by ca. $4 \mathrm{~m}$ wide narrowings, is an undesired and demotivating feature. With the speed differences in the range $30-55 \mathrm{~km} / \mathrm{h}$, the exhaust emissions (including $\mathrm{CO}, \mathrm{CO}_{2}, \mathrm{HC}$, and $\mathrm{NO}_{\mathrm{x}}$ ) can vary considerably, depending on the vehicle type, condition of engine, chosen gear, driving style (standard or aggressive), acceleration/ deceleration value, and also on the longitudinal gradient of the carriageway Conversely, a more defensive driving style with regard to speed, acceleration, and deceleration can reduce these emissions even a few times. When comparing the emission data given in the doctoral dissertation [30], for the speeds of $30 \mathrm{~km} / \mathrm{h}$ and $50 \mathrm{~km} / \mathrm{h}$, we can see over double differences in the emissions of the respective gasses. Bearing this in mind, the siting of the traffic calming measures should be designed with the purpose to encourage defensive driving style, without rapid changes of speed typical of risky and aggressive driving style. When considering what has been said above, we can conclude that horizontal shifts or any other traffic calming treatments used in woonerf should not promote rapid changes of $\Delta \mathrm{v}_{85}$.

The deficiency of parking spaces was found to be the greatest on the section between the test stations P3 and P6. Moreover, frequent illegal parking is a serious concern in this section (Figure 7b).

3.6. Analysis of the Correlation between the Speed Distribution Parameters and Selected Parameters Describing the Traffic Conditions on the Analysed Street

Taking into account the inconclusive results of the statistical tests regarding the relationship between the speed distributions and the pre-defined traffic volume ranges and the direction of traffic the authors decided to investigate the correlation of the relationships of selected speed distribution parameters and the following geometrical parameters that define the traffic conditions on the carriageway (Table 7), i.e., locations of carriageway narrowings and arrangement of parking lanes on the street, specifically:

- carriageway width $(a)$ on the approach to the test station $P i, v=f(a)$,

- carriageway width $(b)$ at the test station $\mathrm{P} 1, v=f(b)$,

- width of the carriageway ahead $(c)$ as seen by the driver at the moment of passing the test station $\mathrm{Pi}, v=f(c)$,

- length of carriageway narrowing on the approach to the test station $(z)$; (only eight such cases were observed in both directions of traffic), $v=f(z)$, and

- length of carriageway narrowing $(w)$ as seen by the driver at the moment of passing the test station; (only seven such cases were observed in both directions of traffic), $v=f(w)$.

The changing visibility of the street ahead, having a prevailing effect on the driver's perception, are presented in Figure 13, below. 


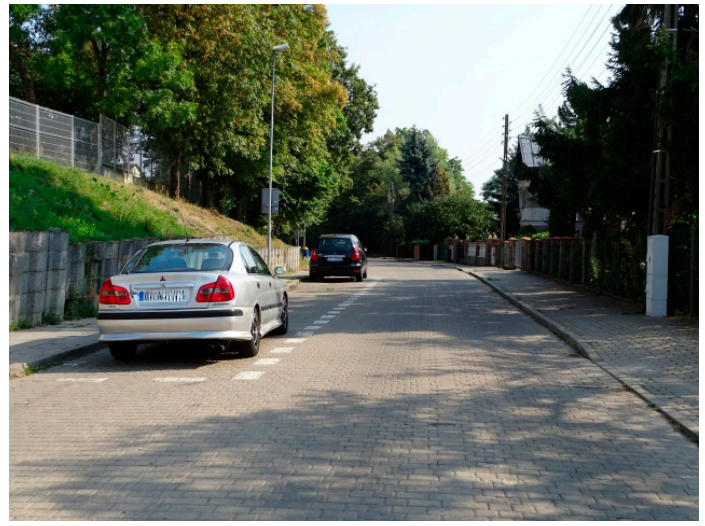

(a)

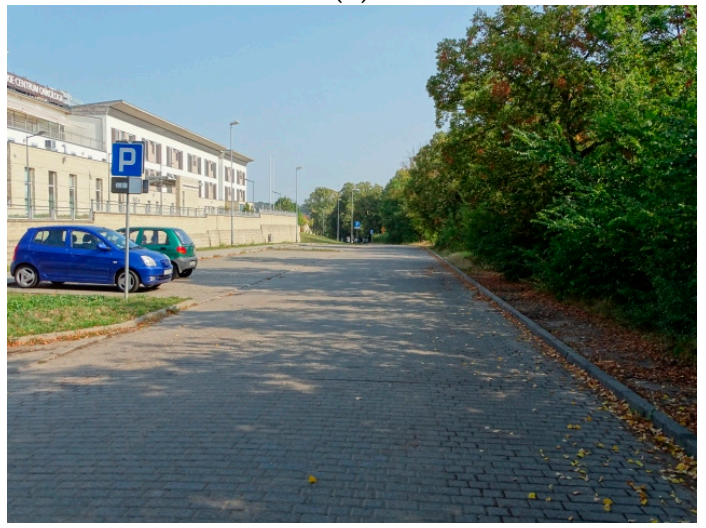

(c)

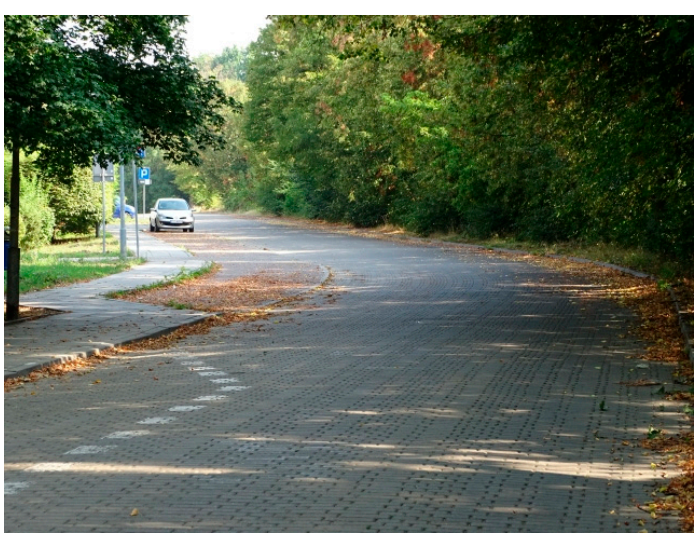

(b)

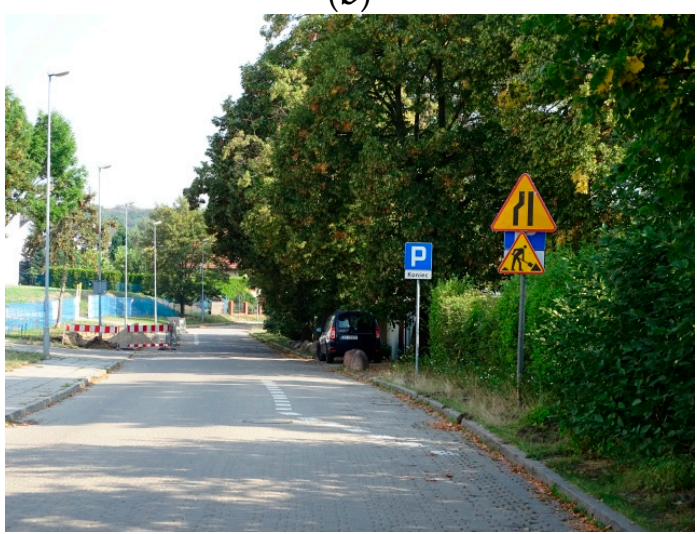

(d)

Figure 13. Changing visibility of the street ahead as seen by the driver: (a) Approach to the test station P2 and a view on the narrowing ahead; (b) View of a wider section, encouraging faster driving at the test station P3; (c) View of a longer section of wider carriageway ahead at the test station P4; and, (d) Approach to the former test station P6 a view on the place where parking places perpendicular to the carriageway centreline are being constructed at the outpatient clinic side.

Table 7. Correlation factors $R$ between the speed distribution parameters and selected parameters describing the traffic conditions on the analysed street.

\begin{tabular}{|c|c|c|c|c|c|}
\hline \multirow{2}{*}{ Speed distribution parameters ${ }^{1}$} & \multicolumn{5}{|c|}{ Analysed functional relationship $R$ : } \\
\hline & $v=f(a)$ & $v=f(b)$ & $v=f(c)$ & $v=f(z)$ & $v=f(w)$ \\
\hline \multicolumn{6}{|c|}{ Traffic volume of $\leq 30 \mathrm{v} / \mathrm{h}$} \\
\hline$v_{85}$ & 0.28 & 0.44 & 0,26 & 0.83 & -0.69 \\
\hline$v_{50}$ & 0.43 & 0.39 & 0.05 & 0.76 & -0.38 \\
\hline$v_{\mathrm{a}}$ & 0.34 & 0.39 & 0.13 & 0.84 & -0.59 \\
\hline \multicolumn{6}{|c|}{ Traffic volume of $30-50 \mathrm{v} / \mathrm{h}$} \\
\hline$v_{85}$ & -0.06 & -0.29 & -0.28 & 0.69 & 0.17 \\
\hline$v_{50}$ & -0.07 & -0.29 & -0.28 & 0.69 & 0.28 \\
\hline$v_{\mathrm{a}}$ & -0.20 & -0.29 & -0.16 & 0.73 & 0.27 \\
\hline \multicolumn{6}{|c|}{ Traffic volume of ca. $100 \mathrm{v} / \mathrm{h}$} \\
\hline$v_{85}$ & -0.10 & 0.08 & -0.06 & $0.82^{2}$ & $0.59^{3}$ \\
\hline$v_{50}$ & -0.09 & -0.16 & -0.22 & $0.78^{2}$ & $0.59^{3}$ \\
\hline$v_{\mathrm{a}}$ & -0.01 & -0.14 & -0.26 & $0.89^{2}$ & $0.50^{3}$ \\
\hline
\end{tabular}

${ }^{1}$ Correlation factors given in relation to the observed speeds in both directions of traffic. ${ }^{2}$ This result is not considered representative since at the traffic volume of ca. $100 \mathrm{v} / \mathrm{h}$ there were only four cases of carriageway narrowing on the approach to the test station. ${ }^{3}$ This result is not considered representative since at the traffic volume of ca. $100 \mathrm{v} / \mathrm{h}$ there were only three cases of carriageway narrowing ahead of the road, as seen by the driver at the moment of passing the test station. 
Based on the analysis of the correlation factor $R$, as compiled in Table 7, it can be stated that the chosen traffic parameters do not significantly affect the speed distribution parameters on the street under analysis. Under the existing traffic conditions, the drivers do not slow down because the existing width Be of the two-way carriageway justifies driving at speeds in the range of $40-70 \mathrm{~km} / \mathrm{h}$. The positive values of the correlation factor $R$ for the $v=f(z)$ relationship provide an additional confirmation that with the carriageway width of $B e$ on the narrowed sections and $B$ beyond them, the speeds increase with the increasing length of the carriageway narrowing. However, the obtained values of the correlation factors specifically concern the studied case and, as such, are should not be considered to be obligatory.

The analysis of the current view of the road ahead, as seen by the driver on the approach to the carriageway narrowing, has a major effect on the driver's perception, triggering specific reactions, such as slowing down when vehicles parked on the parking lane can be seen at the moment (Figure 13a). Conversely, if there are no cars parked there, then the empty, $6.1 \mathrm{~m}$ wide section of the carriageway ahead (Figure 13b,d) will influence the driver's perception, which encourages faster driving, in excess of the woonerf speed limit. The $6.1 \mathrm{~m}$ wide by ca. $250 \mathrm{~m}$ long section of the roadway between the test stations P3 and P6 has a major and profound effect on the driver's perception, which encourages speeding up to over $50 \mathrm{~km} / \mathrm{h}$ with empty street ahead. The hourly traffic volume of ca. $100 \mathrm{v} / \mathrm{h}$ recorded between 8 a.m. and 4 p.m. (Figure 8) indicates that free traffic flow is ensured for almost all of the vehicles travelling down the street. Momentary disturbances are related solely to situations when a driver sees a car driving out of the parking space or coming from the opposite direction.

Moreover, the existing parking lanes do not significantly reduce the view of the carriageway surface free from side obstructions (Figure 13). Presumably the parking lanes, solely designated by line markings, are actually used for parking solely between 8 a.m. and 4 p.m., i.e., during the hospital and the outpatient clinic visiting hours. However, they are quite distant from the hospital entrance, where parking violations are frequently observed (Figure $7 \mathrm{~b}$ ). Beyond these hours, the parking lanes are not used and, as such, they are ineffective in making the drivers slow down to the desired speed of $20 \mathrm{~km} / \mathrm{h}$ (Figures 10 and 12). Therefore, the implementation of woonerf and placement of parking lanes without any side obstructions must be considered to be ineffective in this case. As such, the analysed street does not meet the essential requirements that are defined for woonerf-type streets (Section 1 and Figure 1) and the woonerf entry sign (typical home zone sign-see Figure 11a) is out of place there.

\section{Discussion}

The measurement data show that implementation of woonerf scheme in the analysed street did not follow the fundamental design requirement (i.e., to use appropriate traffic calming treatments) necessary for obtaining a considerable reduction of the vehicle speeds to ca. $20 \mathrm{~km} / \mathrm{h}$. Only one of the woonerf design principles has been followed, namely the lack of pedestrian crossings. The existing traffic infrastructure, including a wide carriageway free of side obstructions (Figures 7 and 13), enabled driving at $40-50 \mathrm{~km} / \mathrm{h}$ or more over almost the entire length of the street, except for the entryway section as shown in Figure 7a. The speed distribution as presented in Figures 10 and 12 confirm that the actual vehicle speeds are much higher than that. Only at the test stations No. P1, P2, and P3 the $85^{\text {th }}$ percentile speed $v_{85}$ in both directions of traffic was less than $35 \mathrm{~km} / \mathrm{h}$ at the traffic volume ranges of $30-50 \mathrm{v} / \mathrm{h}$ and ca. $100 \mathrm{v} / \mathrm{h}$ (Table 3). Unfortunately, a higher value of $85^{\text {th }}$ percentile speed free $v_{85}$ was obtained for lower traffic volumes.

In the analysed street, decreased traffic volumes are observed in the afternoon, night, and morning hours (Figure 8). In turn, higher traffic volumes are observed between 8 a.m. and 4 p.m., i.e., during the hospital and the outpatient clinic visiting hours. It is during that time that the existing parking capacity is exceeded. Higher speeds were observed at these lower traffic volumes on the section between the test stations P3 to P6, i.e., right at the hospital entryways and access gates (Figure 7b).

In line with the results of the study that are presented in [24], the analysis of the speed distribution parameters along the analysed street showed the greatest speed differentials and the steepest speed 
profile right on the above-mentioned section between test stations P3 and P6. According to the principles that Künzler, Dietiker, and Steiner described in [24], the noise and exhaust emissions increase with the increase in the speed differentials and the speed profile inclination. The analysis of $85^{\text {th }}$ percentile speed profiles, as presented in Figure 12, confirms that the noise and exhaust emissions are the highest between 3 p.m and 8 a.m. It is quite the opposite from what was expected when the woonerf scheme was implemented in the analysed street while taking account of the hospital located there, speed reduction being the primary objective. This is because the greatest speed differentials (Figures 10 and 12), noise, and exhaust emissions are observed between the test stations P3 and P6. The authors have proposed a few design options along the street with which it will be possible to obtain ca. 55 additional spaces in the area currently occupied by groves and used for illegal parking when considering the location of the cancer clinic and the demand for increasing the parking capacity (Appendix A). The proposed additional parking lanes should be, in each case, provided with small raised plater beds as the end treatment. The planter beds should be of the type presented in Figure 1, i.e., surrounded by high kerbs, in concrete planters, protected by bollards finished in contrasting colours. This will influence the drivers' perception and should make them slow down. The authors present the proposed measures in Appendix B. In the Authors' opinion, in line with the national guidelines [10-16,21], traffic calming measures that are visible to drivers should be used in all and any woonerven and a narrowing or horizontal shift in view, even in the absence of an any cars in the parking lane, is expected to considerably reduce the vehicle speeds. The expected speed reduction, which results from horizontal treatments, should result in smoother driving along the woonerf street, without sudden changes of speed, excessive noise, or exhaust emissions.

In the existing lawns right in front of the clinic, the authors propose to plant a hedge of violet willow (Salix daphnoides) and thuja (Thuja) or cold-hardy birchleaf spirea (Spiraea betulifolia) as a barrier to sound wave propagation. It is recommended to plant grafted trees at ca. $5 \mathrm{~m}$ intervals before the hedge to improve its sound reducing effect, deciduous (for example dwarf sour cherry "Umbraculifera" (Prunus x eminens "Umbraculifera") alternately with coniferous ones (for example Japanese larch (Larix kaempferi)). These measures will enable maintaining small vehicle speed variations along the most sensitive portion of the street under analysis. At the moment of writing this article, an additional parking lane located beyond the carriageway, comprising fourteen parking bays (Figure 13d), has been completed and the construction of a next large parking lot has been started in the hospital premises. The latter parking is designed to accommodate 174 cars and it has regular access from the woonerf area.

It is proposed to provide a speed table on the western section plus two circular islands (Eselsrücken type) (see Appendix C) on the eastern section since the studied case is actually devoid of gateways, and this has a particularly strong effect on the woonerf entry speeds, as can be seen in the speed profiles.

\section{Conclusions}

The case study that is presented in this article definitely shows that there is no need for the woonerf scheme in the analysed street and the parking lanes designated solely by pavement markings only have a very slight effect on reducing the vehicle speeds to $20 \mathrm{~km} / \mathrm{h}$, even at the traffic volume of ca. $100 \mathrm{v} / \mathrm{h}$. Pedestrian traffic is generally limited to the clinic entry area, which is near the existing parking lanes that are located beyond the carriageway limits. However, in the design, a walkway has been provided on one side of the street only, after the parking lanes, closer to the clinic building. Moreover, no disabled parking bays have been provided. Numerous site visits on the analysed street confirmed frequent parking violations, which, as per the Polish traffic code provisions [9,31], must not be accepted in woonerven.

There is a substantial difference between the analysed street and the other streets that are presented in Figure 1. The authors are of the opinion that the introduction of a $30 \mathrm{~km} / \mathrm{h}$ speed limit (taking account of the close distance to the hospital) and maximising parking capacity would be a sufficient measure in this case. Note, however, that parking lanes that are placed on the side without a walkway must be accompanied by pedestrian crossing installation. In woonerven, pedestrian crossings are 
not used, since the whole carriageway area is available to pedestrians. Therefore, it is possible to keep the woonerf scheme there, subject to increasing the parking lanes capacity to obtain the desired speed reduction.

Moreover, every parking lane should be provided with concrete planters as the end treatment, so as to influence the drivers' perception, communicate the narrowing treatment, and make them slow down also in the absence of parked cars. The placement of side features to communicate the parking lane start and end, horizontal shifts, or narrowings is of primary importance in any woonerf, with the aim of influencing the drivers' behaviour and perception and making them pay attention to the surroundings to facilitate spotting of pedestrians and children playing in the street (see comparison in Figure $13 \mathrm{~b}$ in the main body of the article and Figure A4a,d in Appendix B). For this reason, the woonerf design guidelines limit the length of straight or narrowed section as far as practicable (Table 1). These small distances between the side features influence the driver's perception and, by limiting the view of the street further ahead, make him/her change driving style and slow down.

As a conclusion of the above analyses and discussions, the authors have formulated a few conclusions pointing out the most important issues to be considered by the designers, road administrators, and experts that are involved in defining road traffic standards:

- in the first place, the road administration must define the main role of the street and its function in relation to the surrounding road network to support the choice of Tempo-30 or woonerf scheme, with the latter involving a changed priority of traffic and designation of parking places,

- $\quad$ should the analyses support the decision on implementing woonerf scheme, the design process should start following the sequence that was proposed by the authors of this article and in compliance with the national design guidelines (see Figure 4),

- if the street where woonerf scheme is planned is long (i.e., longer than $600 \mathrm{~m}$ ) and there are public buildings that generate a higher parking space requirement, then in order to keep the project on a limited budget parking lanes should be placed densely and any wider sections, which would encourage speeding up, should be removed and traffic calming treatments should be provided in addition to the parking lanes to utilise their combined effect on the driver's behaviour and perception to enhance spotting of side features and, even more importantly, the pedestrians,

- the chosen design options should ensure smooth, calmed traffic, resulting in reduced exhaust and noise emissions, with good effect on the drivers' attention, influencing his/her behaviour and perception, which results in easier spotting of pedestrians who are given priority in woonerven,

- $\quad$ use of parking lanes while leaving a ca. $4 \mathrm{~m}$ wide carriageway does not provide the desired speed reduction in woonerven if the spacing between the subsequent parking lanes exceeds $50 \mathrm{~m}$; similarly ineffective is leaving a ca. $6 \mathrm{~m}$ wide two-way carriageway,

- parking lanes that are placed on one side of the street at close intervals in the range of 30-50 m will provide speed reduction at a similar level in both directions of traffic, while placing the lanes alternately between the street sides, accompanied by horizontal shifts, depending on the degree of narrowing and the width of carriageway beyond the narrowing can reduce the speeds by up to $7 \mathrm{~km} / \mathrm{h}$, with the exact value depending on the speed on the approach section, the width of the carriageway $B$, and width of the narrowed section $B e$, and

- parking lanes solely designated by pavement markings will not be effective in reducing the vehicle speeds to $\leq 20 \mathrm{~km} / \mathrm{h}$ and vertical end treatments are highly recommended for parking lanes in woonerven, which will increase the visibility of the carriageway narrowing, even when there are no parked vehicles there (see Appendix B).

Author Contributions: Conceptualization, A.S.; methodology, A.S.; formal analysis, A.S. and P.G.; data curation, P.G.; writing — original draft preparation, A.S.; writing—review and editing, A.S.; visualization, A.S. and P.G.; supervision, A.S. All authors have read and agreed to the published version of the manuscript.

Funding: Research was financed by Faculty of Civil Engineering and Architecture of West Pomeranian University of Technology in Szczecin (Szczecin, Poland) from statutory funds. 
Acknowledgments: The authors would like to thank the four anonymous reviewers for their comments which were used to improve the manuscript and add the content concerning Home Zone design features typical of Poland and the issues related to exhaust emissions and the effect of improved visibility of side obstacles on the drivers' perception.

Conflicts of Interest: The authors declare no conflict of interest.

\section{Appendix A}

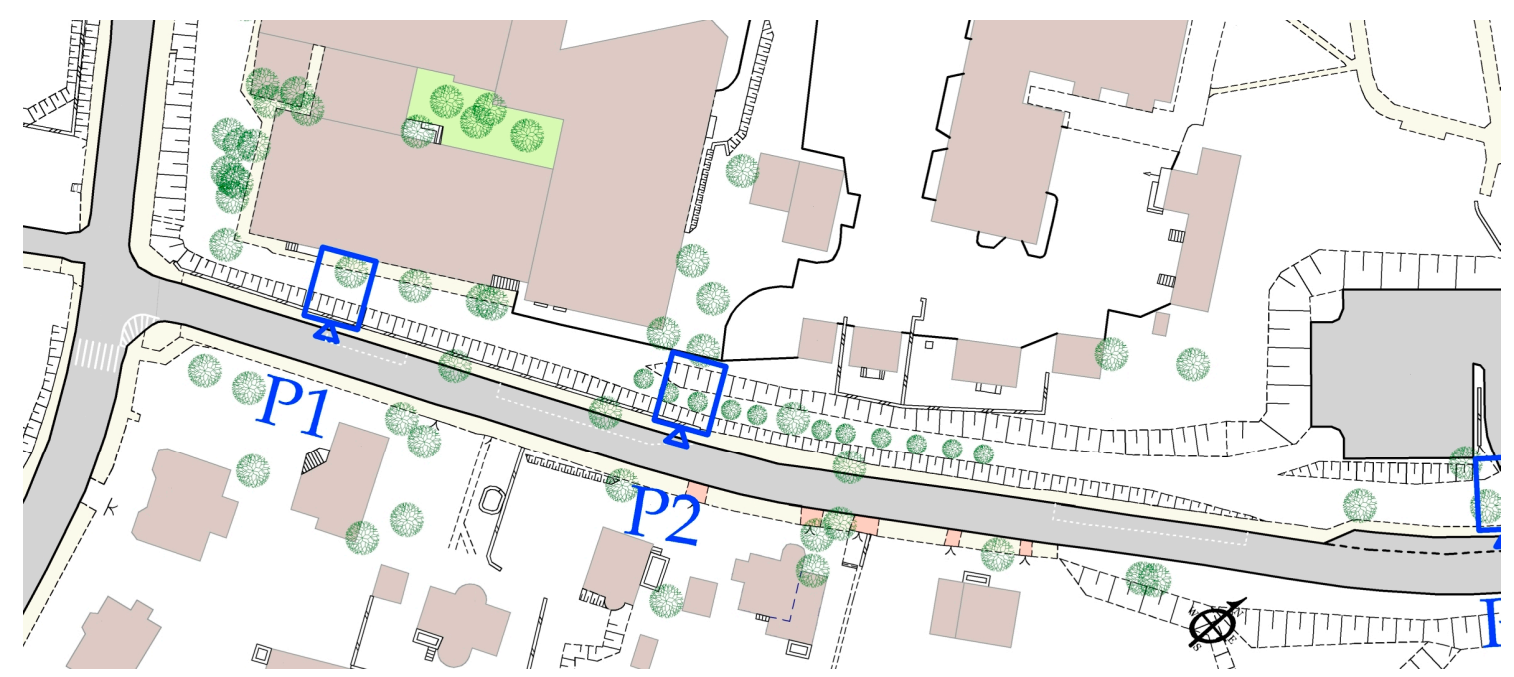

(a)

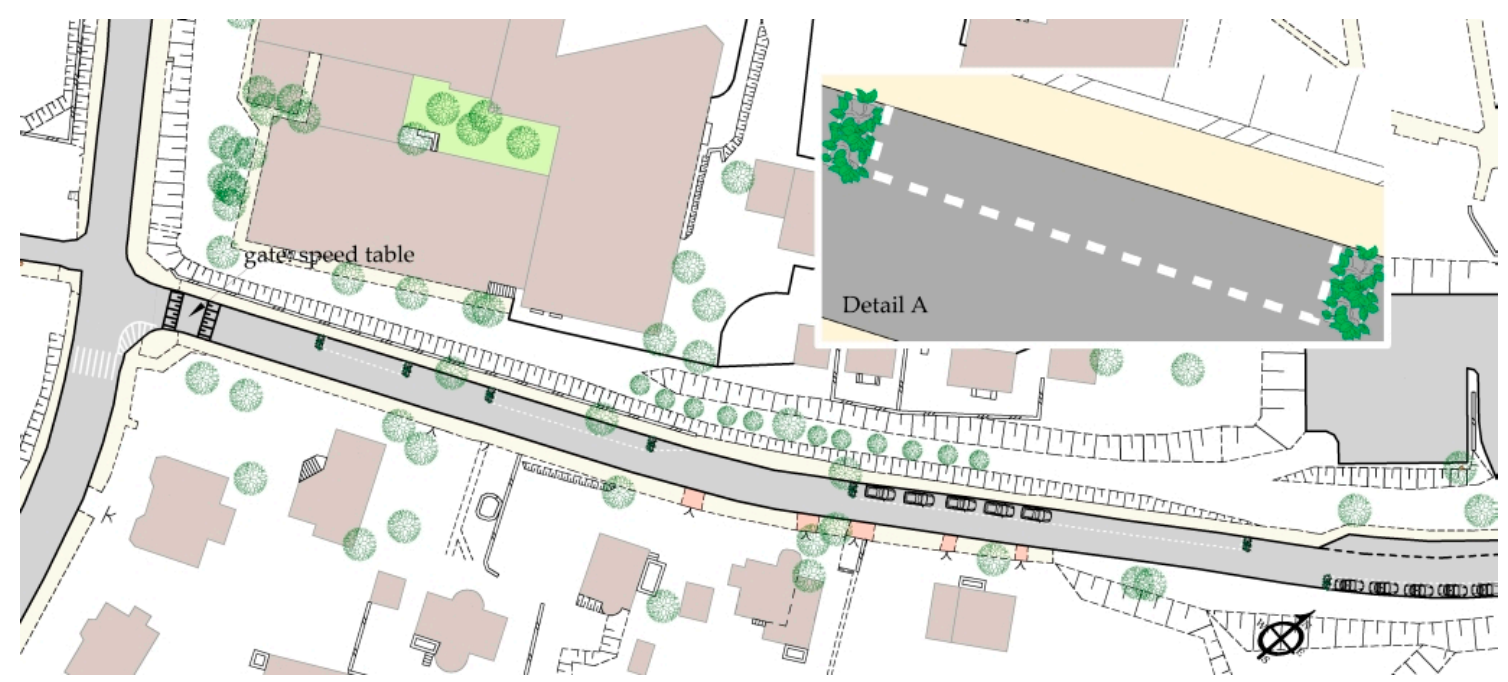

(b)

Figure A1. The analysed woonerf-type street - western section: (a) Before - existing situation; (b) After - the situation after implementation of additional traffic calming treatments, including gateway, concrete planters including plants as the parking lane end treatment and extension of the existing parking lane with additional five parking bays; (Detail A) Concrete planters including plants placed on the carriageway at either end of the parking lane. 


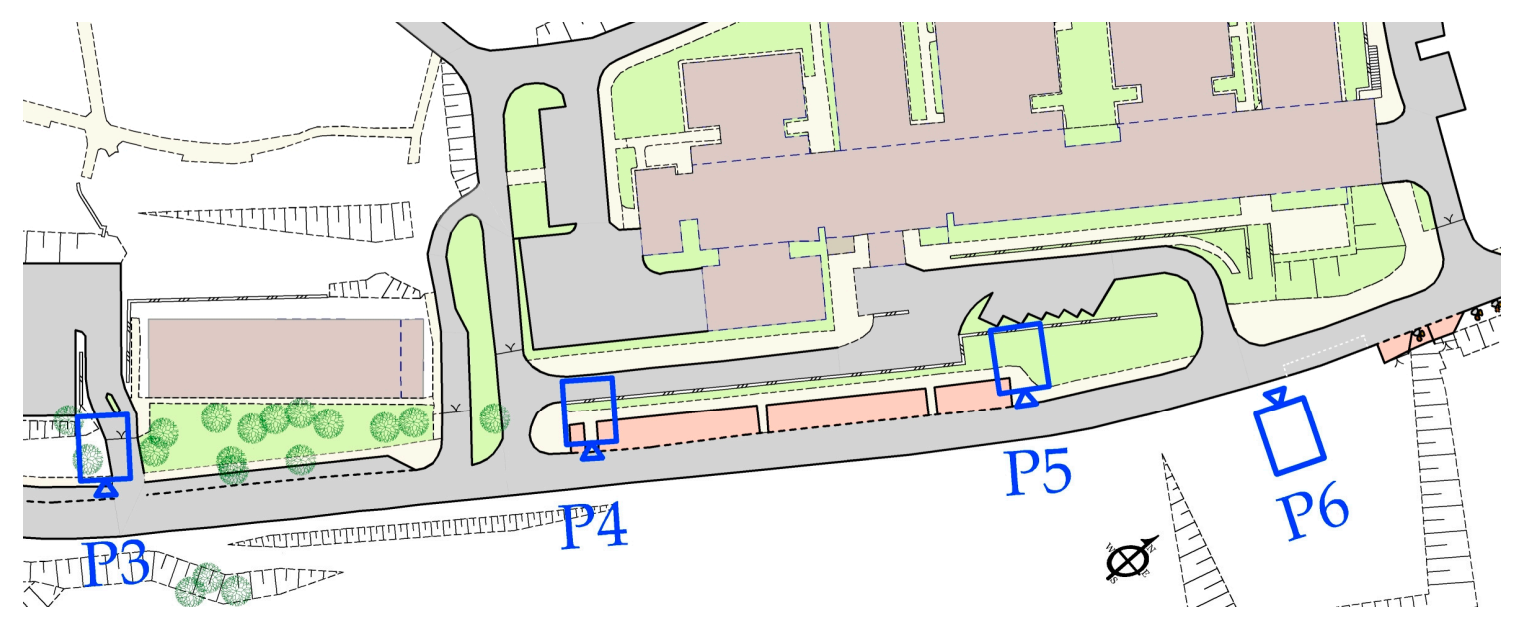

(a)

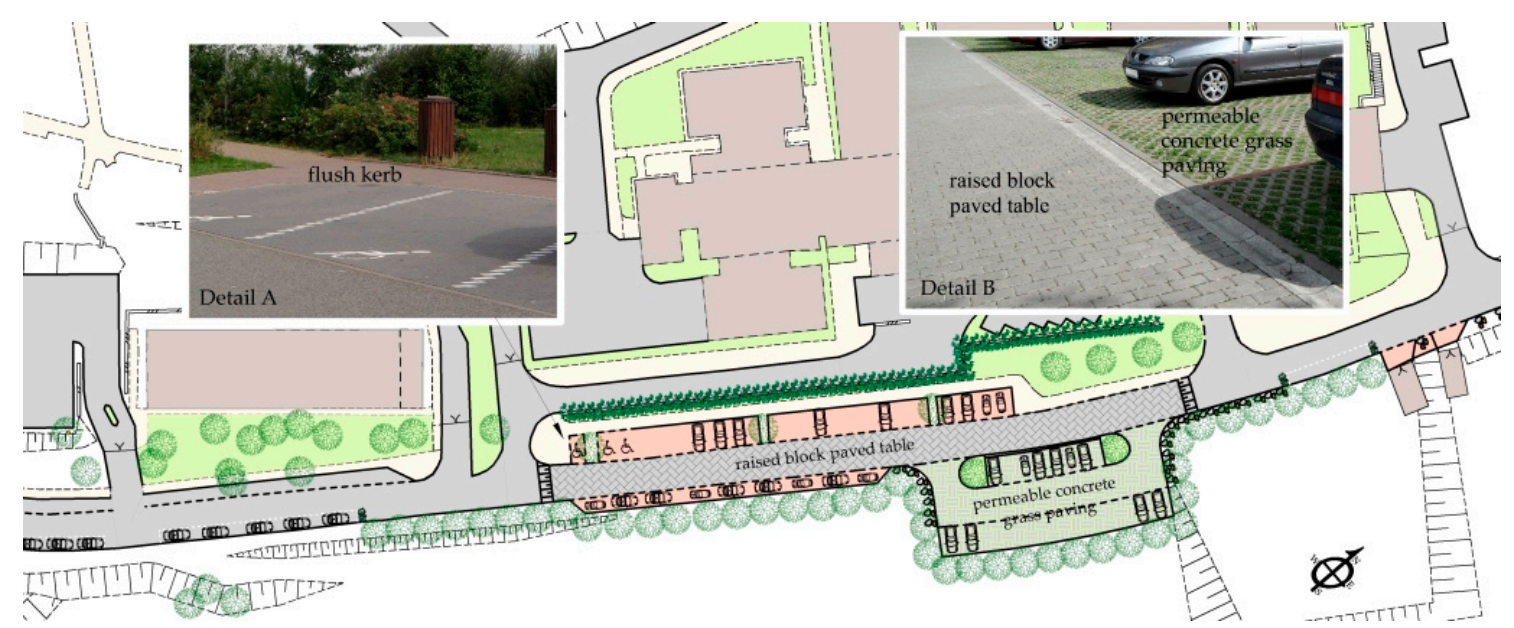

(b)

Figure A2. Analysed woonerf-type street - middle section near the cancer hospital and clinic entryways: (a) Before - existing situation; (b) After - the situation after implementation of additional traffic calming treatments, including concrete planters with plants as the parking lane end treatment, raised block paved table, flush with the kerb to facilitate crossing the street, particularly by persons with impaired mobility, and addition of two parking lanes on the western side of the street as a carriageway narrowing treatment, one traffic lane located beyond the carriageway limits and a parking lot, surfaced with concrete grass pavers located in the area of cleared forest grove; (Detail A) Flush kerb surrounding disabled parking bays; (Detail B) Raised block paved table and permeable concrete grass paving. 


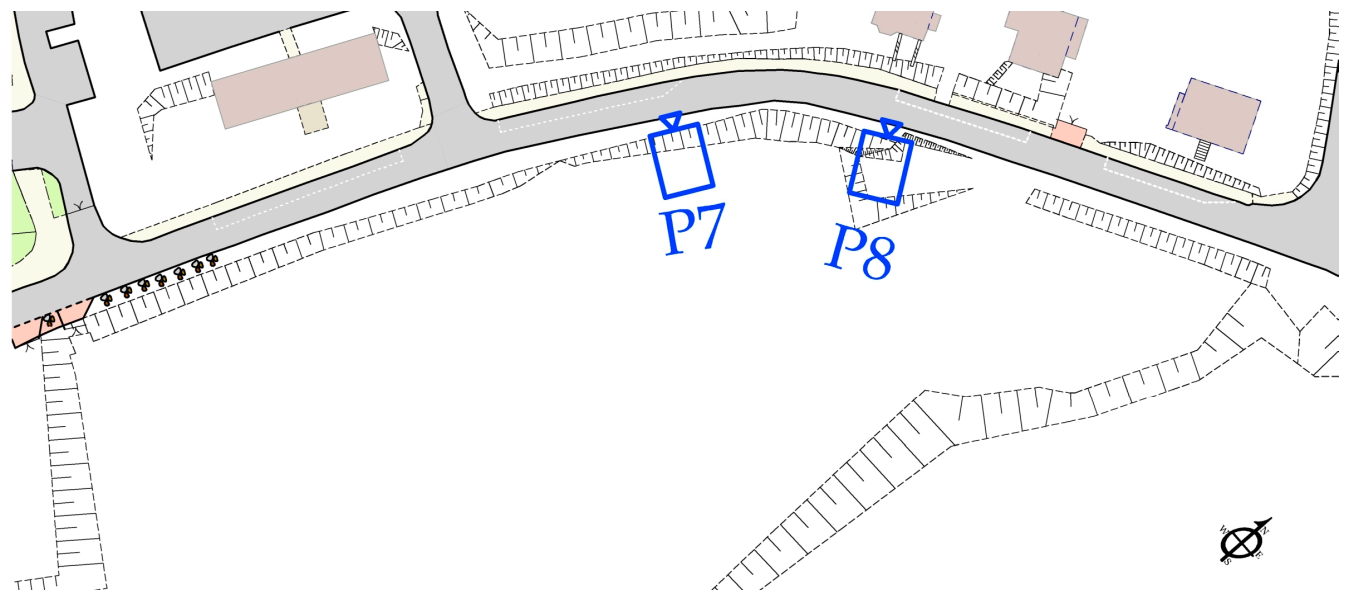

(a)

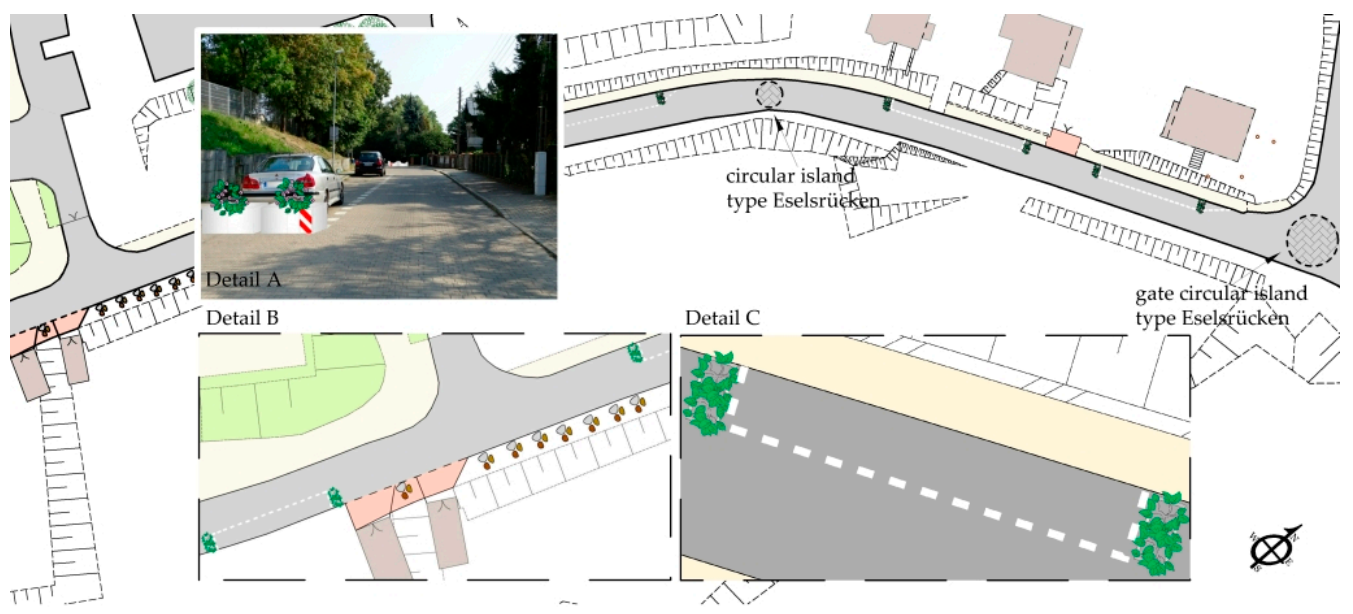

(b)

Figure A3. Analysed woonerf-type street - eastern section: (a) Before - existing situation; (b) After situation after implementation of additional traffic calming treatments: side obstructions and a circular island (type Eselsrücken); (Detail A) Visualisation of planters including plants; (Detail B) Boulders placed near the existing garages and the steep slope; (Detail C) Parking lanes terminated with planters including plants.

\section{Appendix B}

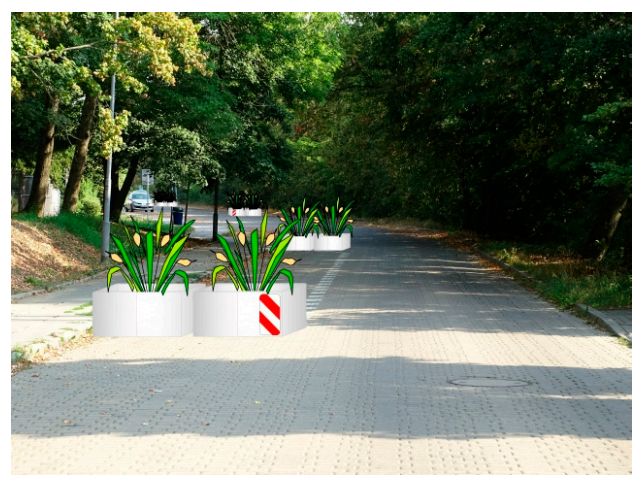

(a)

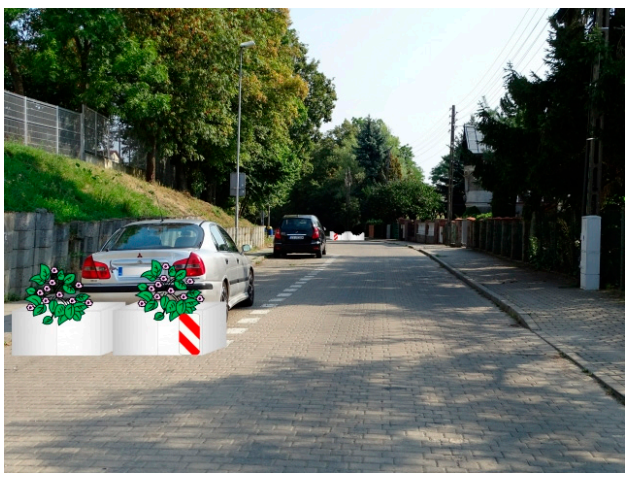

(b)

Figure A4. Cont. 


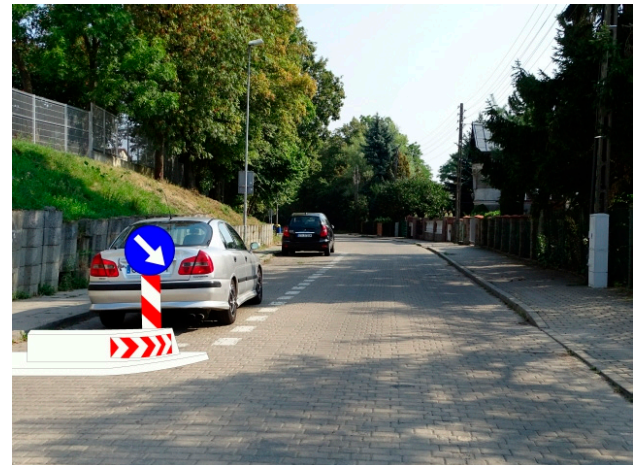

(c)

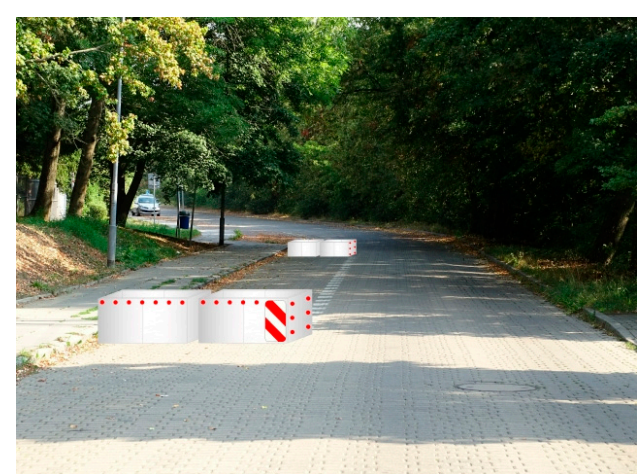

(d)

Figure A4. Visualisation of the proposed vertical elements which should be provided in woonerf streets as parking lane end treatment: (a) Planters with selected ornamental grass species resistant to drought, frost, exhaust emissions and other traffic related pollution; (b) Planters with ornamental shrubs such as aspirin rose (Rose "Aspirin"; (c) PVC blocks (often used in France); (d) Concrete planters including attached LED/ retroreflective devices (used in Germany).

\section{Appendix C}

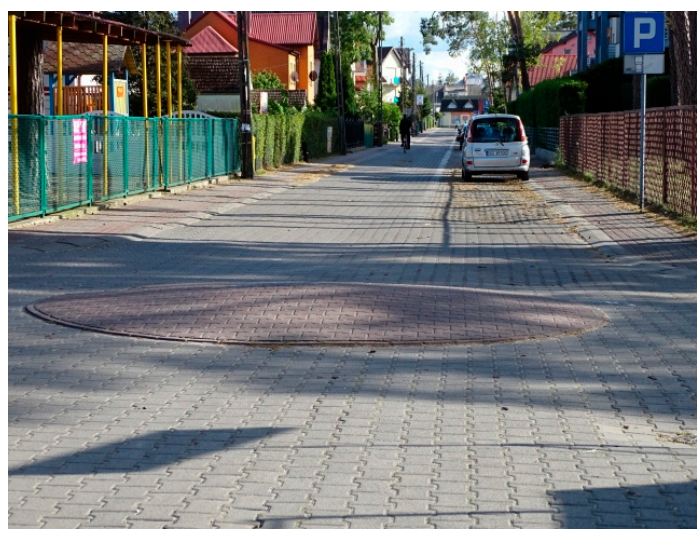

(a)

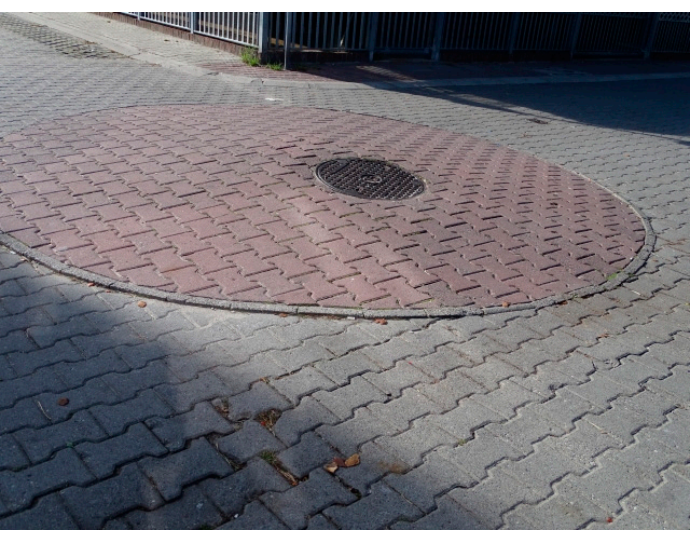

(b)

Figure A5. Example application of a circular island (type Eselsrücken) in a woonerf, implemented in a seaside resort of Miedzywodzie, Poland which, together with parking lanes, provide reduction of speed to somewhere in the region of $15-20 \mathrm{~km} / \mathrm{h}$, in particular in summer: (a) Circular island (type Eselsrücken) installed at the a road junction; (b) Pavement surface details with the manhole cover located on the island slope.

\section{References}

1. Devon County Council. Traffic Calming Guidelines TCG; Engineering and Planning Department: Devon, UK, 1991.

2. Department for Transport; Department for Regional Development (Northern Ireland); Scottish Executives; Welsh Assembly Government. Traffic Calming, Local Transport Note 1/07; TSO: Belfast, Northern Ireland, 2007.

3. Regional Council. Roads Development Guide; Strathclyde Regional Council: East Ayrshire, UK, 2010.

4. Vejdirektoratet. Urban Traffic Areas Part 7 Speed Reducers; Vejdirektoratet: Copenhagen, Denmark, 1991.

5. Stephanie, Paris: Plus de zones à $30 \mathrm{~km} / \mathrm{h}$ dès septembre, Permis A Points PAP 16 August 2014, France. Available online: https://www.permisapoints.fr/actualites/zone-a-30kmh-140815 (accessed on 20 October 2018).

6. Fressancourt, M. Une Limitation de la Vitesse Pour un Meilleur Partage de la Route ... , AQTr 21 June 2011, France. Available online: https://aqtr.com/association/actualites/limitation-vitesse-meilleur-partage-route (accessed on 21 October 2018). 
7. TrinityHaus Civil. Shared Space, Shared Surfaces and Home Zones from a Universal Design Approach for the Urban Environment in Ireland Key Findings \& Recommendations; TrinityHaus Civil, Structural and Environmental Engineering Trinity College Dublin: Dublin, Ireland, 2012; Available online: http://universaldesign.ie/BuiltEnvironment/Shared-Space/Shared-Space-Full-Report.pdf (accessed on 20 October 2018).

8. Wikipedia, Living Street. Available online: https://en.wikipedia.org/wiki/Living_street (accessed on 22 August 2019).

9. AXA Team. Regulations Applicable in Home Zones and Internal Traffic Zones, Article of 18 July 2013. Available online: https://www.smartdriver.pl/przepisy-obowiazujace-w-strefach-ruchu-i-zamieszkania? categoryName=bezpieczenstwo,Poland (accessed on 22 July 2019).

10. SWOV. 30 km/h Zones, SWOV Fact Sheet; Instituut voor Wetenschappelijk Onderzoek Verkeersveiligheid: Haag, The Netherlands, 2018; Available online: https://www.swov.nl/feiten-cijfers/factsheet/30kmuur-gebieden (accessed on 15 August 2019).

11. Woonerven; MENSenSTRAAT: Delft, The Netherlands, 2018; Available online: http://www.mensenstraat.nl/ inspiratie/woonerven/ (accessed on 22 August 2019).

12. Institute of Highway Incorporated Engineers. Home Zone Design Guidelines; HQ Design \& Print: Essex, UK, 2002; Available online: https://www.theihe.org/wp-content/uploads/2019/03/Home-Zone-Design-Guideline. pdf (accessed on 20 August 2019).

13. Janssens, I.; Chalanton, I.; Bertrand, P.-J.; Caelen, E.; Broeckaert, M.; Dullaert, I.; Englebin, Y.; Houdmont, A.; Mathieu, V.; Temmerman, P.; et al. Het (Woon) Erf, Brochure ter Attentie van de Weg Beheerders; Belgisch Institut voor de Verkeersveiligheid BIVV: Brussel, Belgium, 2013; Available online: https://webshop.bivv.be/frontend/ files/products/pdf/fa190b14bb74dfbe89179cd512d173e9/web_2013_zr_nl.pdf (accessed on 22 August 2019).

14. Bureau suisse de prevention des accidents BPA. Brochure technique Zones 30; Bureau suisse de prevention des accidents BPA: Bern, Switzerland, 2011; Available online: https://www.police-du-chablais.ch/N603/circulerdans-les-zones-30-km/h.html (accessed on 22 August 2019).

15. Touring Club Schweiz TCS. Sicherheit in den Quartieren, Eine Informationsschrift über Strassengestaltung und Verkehrsmassnahmen; TCS CHF 10; Touring Club Schweiz Verkehrssicherheit: Vernier, Switzerland, 2002; Available online: https:/www.mein-wiesendangen.ch/index.php/files/21/Verschiedenes/24/tcs-sicherheit-inden-quartieren.pdf (accessed on 22 August 2019).

16. Biddulph, M. Home Zones: A Planning and Design Handbook; The Policy Press and the Joseph Rowntree Foundation: Southampton, UK, 2001; Available online: https:/www.researchgate.net/publication/267624323_ Home_zones_A_planning_and_design_handbook (accessed on 17 August 2019).

17. Huguenin-Richard, F. La Mobilité des Enfants à L'épreuve de la Rue Impacts de L'aménagement de Zones 30 sur Leurs Comportements; Enfances Familles Générations EFG: France, 2010; pp. 66-87. Available online: https://doi.org/10.7202/044393ar (accessed on 28 August 2019).

18. Allinger-Csollich, E. Begegnungszonen: Kriterien-Gestaltung-BürgerInnenbeteiligung. Gemeinden Lebenswert Gestalten Sachgebiet Verkehrsplanung, Amt der Tiroler Landesregierung, Abteilung Verkehr und Straße; Sachgebiet Verkehrsplanung: Innsbruck, Austria, 2016; Available online: https://www.tirol.gv.at/fileadmin/themen/ verkehr/verkehrsplanung/downloads/mobile06_16_web.pdf (accessed on 20 August 2019).

19. Speed Humps vs. Speed Bumps. Germany. 2010. Available online: https://www.stmarysmd.com/docs/ speedbumpsvshumps.pdf (accessed on 20 August 2019).

20. Google Earth. 2019. Available online: http://www.earth.google.com (accessed on 19 September 2019).

21. Road and Transportation Research Association Directives for the Design of Urban Roads; RASt 06; Road and Transportation Research Association: Köln, Germany, 2012.

22. Department for Transport; Scottish Executives. Traffic Calming, Local Transport Note 1; The Stationery Office TSO: London, UK, 2007. Available online: https://www.gov.uk/government/publications/traffic-calming-ltn107 (accessed on 12 August 2019).

23. Speed Displays Traffic Detection, Radar, Detection, Software, Vitronic; Kędzierzyn Koźle, Poland, 2015.

24. Künzler, P.; Dietiker, J.; Steiner, R. Nachhaltige Gestaltung von Verkehrsräumen im Siedlungsbereich, Grundlagen für Planung, Bau und Reparatur von Verkehrsräumen; Herausgegeben vom Bundesamt für Umwelt BAFU: Bern, Switzerland, 2011; Available online: https://www.bafu.admin.ch/dam/bafu/de/dokumente/luft/uw-umweltwissen/nachhaltige_gestaltungvonverkehrsraeumenimsiedlungsbereich.pdf (accessed on 12 August 2019). 
25. Nina67, Consommation D'essence en Fonction de Vitesse et Rapport, Astuces-Pratiques, Article of 23 July 2015. Available online: https://www.astuces-pratiques.fr/auto-moto/consommation-d-essence-enfonction-de-vitesse-et-rapport (accessed on 12 August 2019).

26. Delacrétaz, Y. Quel Aménagement Pour Quelle Vitesse? Les «Marges de Manouvre» en Milieu Urbain; Schweizerischen Vereinigung der Verkehrsingenieure und Verkehrsexperten SVI, Présentation: Mobilité et transports, 4 November 2014; Lausanne, Switzerland, 2014; Available online: http://www.svi.ch/fileadmin/ geschwindigkeiten/Presentation_Delacretaz_SVI_2014.pdf (accessed on 22 August 2019).

27. KB, Verkeerswereld Geeft te Weinig Aandacht aan Woonerf, Verkeerskunde, Mensenstraat April 2012. Available online: https://www.mensenstraat.nl//wp-content/uploads/2013/06/verkeerskunde2012-04woonerf. pdf (accessed on 22 August 2019).

28. Bigazzi, A.Y.; Rouleau, M. Can traffic management strategies improve urban air quality? A review of the evidence. J. Transp. Health 2017, 7, 111-124. [CrossRef]

29. Nocera, S.; Ruiz-Alarcón Quintero, C.; Cavallaro, F. Assessing carbon emissions from road transport through traffic flow estimators. Transp. Res. Part C Emerg. Technol. 2018, 95, 125-148. [CrossRef]

30. Andrzejewski, M. The Effect of the Driving Style on Fuel Consumption and Amount of Harmful Exhaust Gas Emissions. Ph.D. Thesis, Poznań University of Technology, Poznań, Poland, 2013. Available online: http://repozytorium.put.poznan.pl/Content/285883/Maciej_Andrzejewski_Wplyw_ stylu_jazdy_kierowcy_na_zuzycie_paliwa_i_emisje_substancji_szkodliwych_w_spalinach.pdf (accessed on 16 December 2019).

31. Tański, M. Parking in Home Zones. Polish Traffic Code. Article of 13 March 2019; Poland. 2019. Available online: https://www.prawodrogowe.pl/informacje/ekspert-wyjasnia/parkowanie-w-strefiezamieszkania-wyjasnia-ml-insp-mariusz-tansk (accessed on 10 August 2019).

(C) 2020 by the authors. Licensee MDPI, Basel, Switzerland. This article is an open access article distributed under the terms and conditions of the Creative Commons Attribution (CC BY) license (http://creativecommons.org/licenses/by/4.0/). 